\title{
Geologisch-bodenkundliche Untersuchungen an den Niederterrassenfeldern bei Basel unter besonderer Berücksichtigung der spätlatènezeitlichen Fundstelle Basel-Gasfabrik
}

\author{
Philippe Rentzel
}

Zusammenfassung / Abstract .............................31

Einleitung 34

A. Quartärgeologische Aspekte: Bodenbildungen auf der Niederterrasse zwischen Augst und Basel 34

1. Kaiseraugst „Im Sager" ................................. 35

2. Augst „Kastelen“ ..................................... 36

3. Muttenz „Kiesgrube Meyer-Spinnler“ ........... 37

4. Basel-Münsterhügel „Rittergasse 4“ ............. 39

5. Basel „Bäumleingasse 14“ .......................... 40

6. Kaiseraugst „Kastell, Jakobli-Haus“.............. 41

7. Basel-Gasfabrik „Fabrikstrasse 5“ .............. 42

8. Schlussfolgerungen .............................. 43

B. Geoarchäologische Untersuchungen zur

Fundstelle Basel-Gasfabrik.

1. Topographische und bodenkundliche Verhältnisse nördlich von Gaskessel 7 (Fabrikstrasse)

2. Spätlatènezeitliche Ablagerungen ............... 46

2.1 Ein Lehmboden................................... 46

2.2 Planieschichten .................................. 49

2.3 Deutung .............................................. 50

3. Schlussfolgerungen ............................. 50

Bibliographie .... 51

\section{Zusammenfassung}

Im ersten Teil des Aufsatzes werden quartärgeologisch-bodenkundliche Untersuchungsergebnisse an Aufschlüssen der linksrheinischen Niederterrasse bei Basel vorgelegt. Ausgehend von der morphologischen Gliederung der Niederterrassenfelder durch WITTMANN (1961), erlauben die neuen geowissenschaftlichen Analysen eine chronologische Einordnung einzelner Teilfelder. Für das höchstgelegene A1- (und A2-) Feld wird ein hochglazialer Datierungsansatz (Jungwürm) postuliert. Die Bildung des nächsttieferen A3-Feldes muss aufgrund palynologischer Evidenzen bereits vor oder spätestens während des Bölling-Interstadials erfolgt sein, da die Rheinschotter im Stadtgebiet von Basel (Aufschluss „Basel-Bäumleingasse“) partiell von spätglazialen Altarmablagerungen bedeckt sind. In den übrigen untersuchten Profilaufschlüssen der AFelder sind die Rheinschotter von einer stark verwitterten, rötlich gefärbten Bodenbildung (Parabraunerde) erfasst, deren Entwicklung folglich im oder bereits vor dem Bölling-Interstadial eingesetzt hat. Der genetischen Deutung der Schotterterrassen - laut
WitTMAnn (1961) soll es sich beim höchstgelegenen A1-Feld um ein Akkumulationsniveau, bei allen tieferen A- und B-Feldern um Erosionsstufen handeln wird nicht weiter nachgegangen. Die Schotter des tiefliegenden B3-Feldes sind bei Kaiseraugst und in Basel von einem bis $2 \mathrm{~m}$ mächtigen Hochflutsand bedeckt, der an der Basis eine atlantische Molluskenfauna führt. In diesen feinkörnigen Alluvialsedimenten entwickelte sich bis zum ersten vorchristlichen Jahrhundert eine schwach ausgeprägte Parabraunerde. Im zweiten Teil werden Resultate mikromorphologischer Analysen an archäologischen Sedimenten der Fundstelle Basel-Gasfabrik diskutiert. Aufgrund der künstlich gekappten Bodenprofile steht fest, dass zu Beginn der latènezeitlichen Besiedlung ein beträchtlicher Abtrag von Bodenmaterial stattgefunden hat. An der Basis der archäologischen Schichtenfolge liess sich indessen mehrfach ein Stampflehmboden beobachten, der mit Hausstrukturen in Verbindung gestanden haben muss. Dieser unterste antike Gehhorizont wird von Lehmplanien - zur Hauptsache aus verwitterten, jedoch unverbrannten Lehmwänden bestehend - überdeckt, die auch das unterste archäologische Fundniveau einschliessen. Dieses fundreiche, feinkiesige Niveau ("Kieselischicht") wird in gleicher Weise als Planie gedeutet und nicht als längerfristig offenliegender Gehhorizont. Es kann gezeigt werden, dass die aus der anthropogenen Tätigkeit resultierende archäologische Schichtenfolge sich aus Sedimenten „urbanen“ Charakters aufbaut, die letztlich den "dark earth" Ablagerungen (MACPHAIL 1994) nahestehen.

\section{Abstract $^{1}$ \\ A geological and pedological study of the Lower Rhine Terrace near Basel (Switzerland) with special regards to the late Latène site of Basel-Gasfabrik}

In the first part of the paper we present the results of a geological and pedological study of alluvial deposits of the Lower Rhine Terrace (Niederterrasse) near Basel. Based on the morphological classification of the terrace levels by WITTMANN (1961), the new geological investigations allow a chronological assignment of some of the gravel levels.

The highest gravel level of the Lower Rhine Terrace (level A1, Wittmann 1961) seems to have been formed during the Upper Wurmian Pleniglacial. According to new palynological results, the formation of the A3level was finished before or at the latest during the Bölling-Interstadial, indicated by late-glacial fluvial 


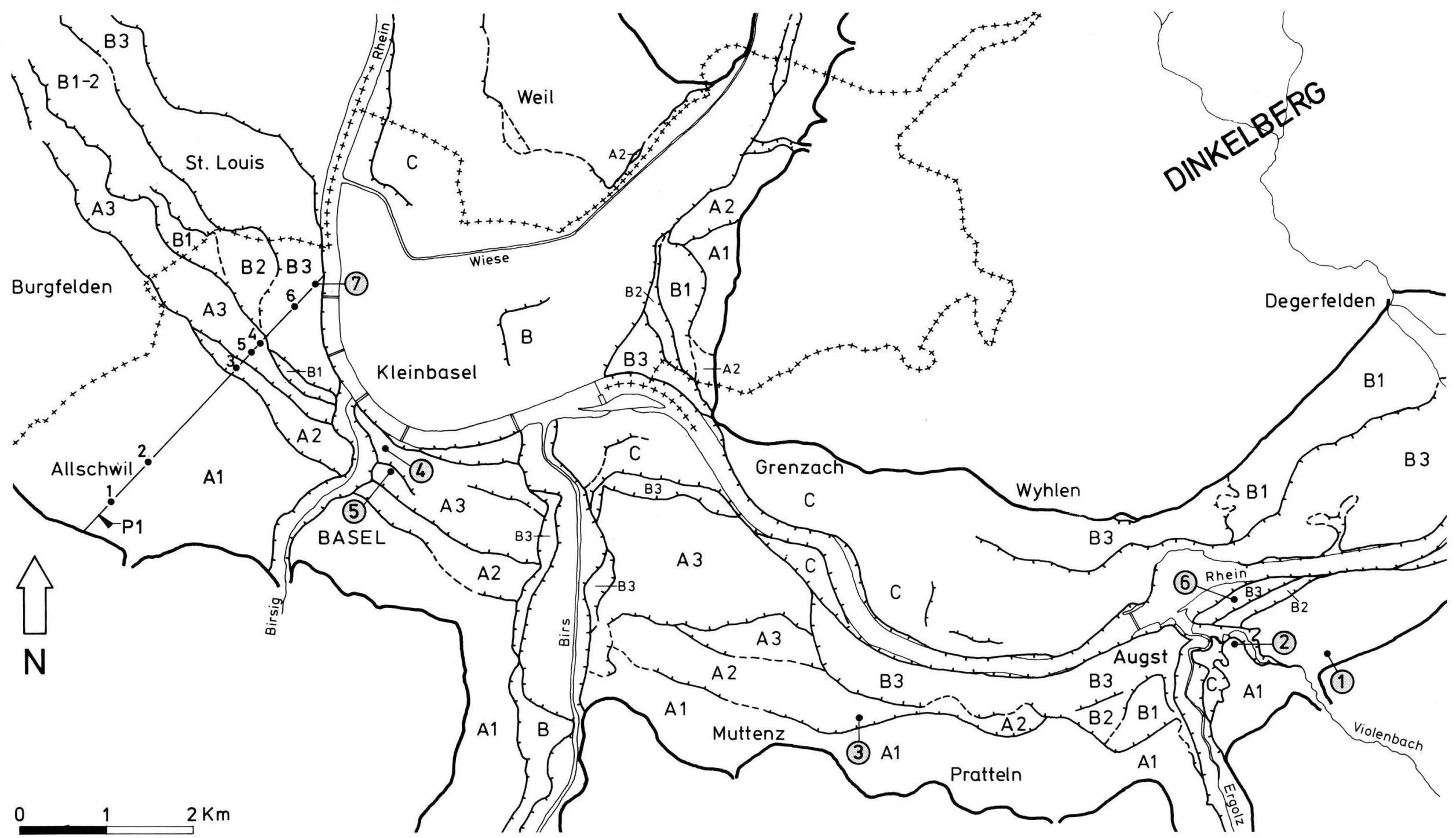

Abb. 1a. Quartärgeologische Übersichtskarte des Hochrheintals zwischen Basel und Augst. Eingetragen sind die Niederterrassenfelder (Teilfelder A, B und C nach WITTMAnN 1961) sowie die Lage der untersuchten Bodenprofile 1-7. Die untersuchten Aufschlüsse 1-6 wurden zusätzlich auf die Profilspur P1 projeziert.

\section{Legende:}

1 Kaiseraugst Im Sager" 2 Augst Kastelen" 3 Muttenz "Kiesgrube Meyer-Spinnler"

6 Kaiseraugst "Kastell, Jakoblihaus" 7 Basel-Gasfabrik "Fabrikstrasse 5“ 


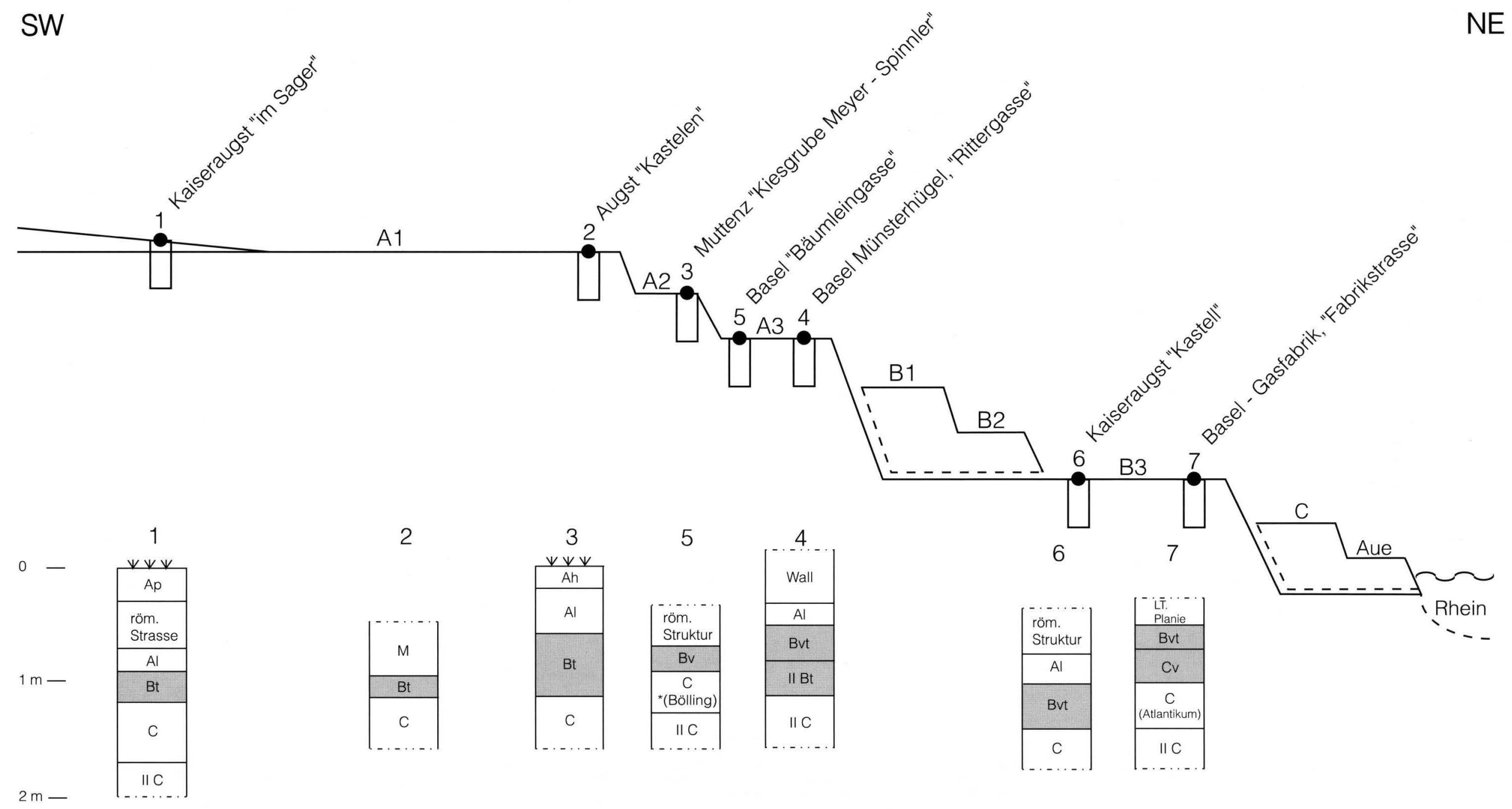

Abb. 1b. Idealisiertes Querprofil P1 durch die Niederterrassenfelder bei Basel, mit der Lage der untersuchten Bodenprofile. Unten: Wiedergabe der Bodenprofile 1-7 in stark schematisierter Form (s. dazu auch Abb. 2-8). 
deposits, covering the unweathered Rhine gravels on the outcrop Basel-Bäumleingasse. In most places of the A-levels, characteristic soils were formed on the top of Rhine gravels. These soils reached a strong degree of alteration and correspond to a reddish argillic brown earth with a kaolinite-rich illuvial horizon. As shown by the palynologically dated gravels at Basel-Bäumleingasse, pedogenesis on the A-levels began during or even before the Bölling-Interstadial. The genetic interpretation of the terrace formation is not being discussed here. According to WITTMAnN (1961) only the highest (A1) terrace results from the accumulation by a braided-river system, all the younger levels (A2 B3) deriving from fluvial erosion. The Rhine gravels of the deep-seated B3 terrace are covered with some 2 $\mathrm{m}$ of sandy flood-plain deposit containing at the base molluscs of Atlantic age (outcrop Basel-Gasfabrik). Soil developement in these calcareous sands led to an argillic brown earth showing a faintly marked illuvial horizon until the late Latène period.

The second part of the study deals with micromorphological investigations on archaeological sediments from the late Latène site of Basel-Gasfabrik. Artifically truncated soil profiles indicate a considerable loss of top soil material at the beginning of the Latène settlement. At the base of the archaeological sequence, a mud floor probably belonging to huts was found in several micromorphological samples. This sterile Latène occupation surface - invisible during field work was covered with some $30 \mathrm{~cm}$ of loamy dumps that resulted essentially from disaggregation of unburned daub. Few centimeters above the clay floor, the lowest Latène artifact level contained various dumped finds and showed no evidence of trampling. Therefore this gravel-rich artifact horizon does not represent a living floor. It can be demonstrated that the archaeological sequence, as a result of anthropogenic activities, consists mainly of "urban" sediments that resemble the dark earth deposits (MACPHAIL 1994).

\section{Key-words}

Lower Rhine Terrace, gravels, soils, micromorphology, chronology, flood plain deposit, archaeology, Latène period, clay floor, dump, daub, dark earth.

\section{Einleitung}

Der folgende Beitrag geht auf die natürlich entstandenen und anthropogen geprägten Ablagerungen ein, die bei archäologischen Ausgrabungen in der spätlatènezeitlichen Fundstelle Basel-Gasfabrik angetroffen wurden. Da die Sedimentationsgeschichte und die vorlatènezeitliche Bodenentwicklung auf der aus Schottern und Hochflutsanden aufgebauten Ebene der Gasfabrik (zum grössten Teil Areal der Firma Sandoz) aus quartärgeologischer Sicht nicht isoliert betrachtet werden können, erschien eine Ausweitung der bodenkundlichen Untersuchungen auf weitere Aufschlüsse im Bereich der Niederterrasse zwischen Augst und Basel erforderlich. Dadurch soll das grundlegende Werk von Wittmann (1961) über die Gliederung der Niederterrasse um punktuelle pedologische Aufnahmen ergänzt und erweitert werden. Der erste Teil der vorliegenden Arbeit befasst sich mit den Ergebnissen dieser mikromorphologischen, palynologischen und malakologischen Untersuchungen sowie den daraus abgeleiteten Schlussfolgerungen bezüglich der Zeitstellung einzelner Niederterrassenfelder. Anschliessend behandelt ein zweiter Teil die Bodenbildungen, die spätlatènezeitlichen Gehniveaus und die Planieschichten im Bereich der archäologischen Grabungen nördlich von Gaskessel 7 an der „Fabrikstrasse 5", Areal Firma Sandoz.

\section{A. Quartärgeologische Aspekte: Bodenbildungen auf der Niederterrasse zwischen Augst und Basel}

\section{Übersicht}

Im gesamten Ober- und Hochrheintal besteht der geologische Untergrund über weite Bereiche aus den fluvioglazialen und fluviatilen Ablagerungen des Rheins ( $F$ ISCHER et al. 1971, Müller et al. 1984), die im Rahmen dieser Arbeit exemplarisch für den linksufrigen Abschnitt zwischen Basel und der flussaufwärts gelegenen Gemeinde Augst näher vorgestellt werden (Abb. 1a). Rheinschotter und teils auch Hochflutsande bauen die weiten Ebenen der Niederterrasse im erwähnten Abschnitt auf und werden - je nach Ausgangsgestein und geomorphologischer Lage - von unterschiedlich ausgeprägten Verwitterungsdecken (Bodenbildungen) überlagert. Im freien Gelände kann die Niederterrasse in mehrere, gegen den heutigen Rheinlauf hin abgetreppte Niveaus - sog. Einzelfelder - gegliedert werden, wobei dieser morphologischen Gliederung aufgrund der sukzessiven Flusserosion gleichzeitig eine relativchronologische Bedeutung zukommt: Die topographisch hochgelegenen A-Felder müssen vor den tieferen B-Feldern entstanden sein, und letztere sind wiederum älter als das unterste, nach SCHMID (1950) ins Subatlantikum zu datierende C-Feld (Abb. 1b). Während sich die Unterteilung der Niederterrasse in höhere A-Felder (mit den drei Teilfeldern A1, A2 und A3) und tiefere B-Felder (Teilfelder B1, B2 und B3) allgemein etabliert hat, so wird deren zeitliche Einordnung kontrovers diskutiert, da ausser für das C-Feld nahezu keine chronostratigraphischen Fixpunkte bekannt sind (WITTMANn 1961, Graul 1962). Im folgenden Abschnitt werden neue bodenkundliche Untersuchungsergebnisse und chronologische Daten in knapper Form vorgelegt $^{2}$, die - mit Ausnahme des Aufschlusses von Muttenz "Kiesgrube Meyer-Spinnler" - anhand von Stratigraphien archäologischer Ausgrabungen erarbeitet wurden ${ }^{3}$. 


\section{Kaiseraugst „Im Sager“}

Geologisch-bodenkundliche Situation: Polygenetische Parabraunerde aus lösshaltiger Solifluktionsdecke über Niederterrassenschottern (Teilfeld A1).
Archäologischer Bezug: Römische Tonentnahmegruben durchschlagen die Parabraunerde.

Koordinaten: 622'375/264'900

Höhe: 294 m ü. M.

Literatur: LASSAU 1995

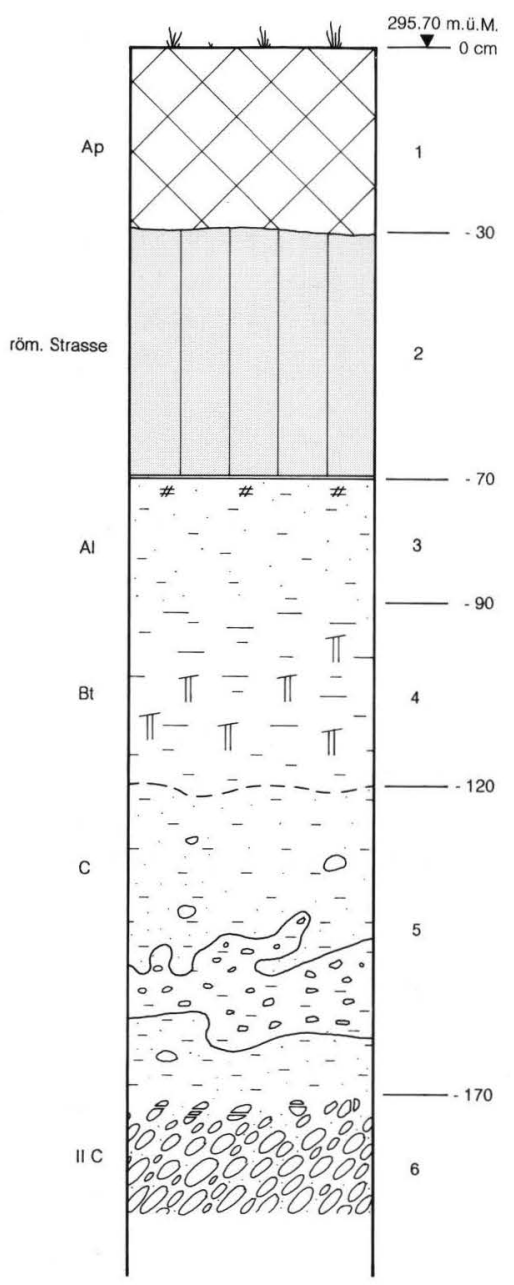

Resultate der mikromorphologischen Bodenuntersuchungen: Kaiseraugst Im Sager (1994.13)

\begin{tabular}{|c|c|c|c|}
\hline & Beschrieb & $\begin{array}{l}\text { Mikromorphologische } \\
\text { Merkmale }\end{array}$ & Interpretation \\
\hline 1 & $\begin{array}{l}\text { Dunkelbrauner, } \\
\text { humöser siltiger } \\
\text { Lehm. }\end{array}$ & $\begin{array}{l}\text { (Keine mikromorphologische } \\
\text { Analyse) }\end{array}$ & Aktueller Pflughorizont. \\
\hline 2 & $\begin{array}{l}\text { Gelber, siltiger Lehm, } \\
\text { mit etwas rötlichem Kies }\end{array}$ & $\begin{array}{l}\text { Heterogener Aspekt, siltige } \\
\text { und feinsandige Zonen. } \\
\text { Starke Kompaktion. }\end{array}$ & Römischer Strassenkoffer. \\
\hline 3 & $\begin{array}{l}\text { Hellgelber, siltiger } \\
\text { Feinsand, vereinzelte } \\
\text { Holzkohlen. }\end{array}$ & Tonauswaschung, Bleichung. & $\begin{array}{l}\text { Eluvialhorizont, } \\
\text { durch römische Eingriffe } \\
\text { gekappt. }\end{array}$ \\
\hline 4 & $\begin{array}{l}\text { Dunkelbrauner, toniger } \\
\text { Lehm, mit Eisen- und } \\
\text { Manganausfällungen. }\end{array}$ & $\begin{array}{l}\text { Tonanreicherung, in } 3 \text { Phasen } \\
\text { 1. ( älteste) Phase: Illuvation } \\
\text { rötlich gelber Tontapeten, } \\
\text { diese oft in Matrix einge- } \\
\text { arbeitet. 2. Phase: Gelbe } \\
\text { Tonablagerungen in Poren, } \\
\text { hydromorph überprägt. } \\
\text { 3. Phase: Einwaschung } \\
\text { eines braunen,organischen } \\
\text { Siltes. (Abb. 2b) }\end{array}$ & $\begin{array}{l}\text { Mehrphasiger Illuvialhorizont } \\
\text { einer Parabraunerde aus } \\
\text { Schwemmlöss. }\end{array}$ \\
\hline 5 & $\begin{array}{l}\text { Gelbbrauner, sandig- } \\
\text { siltiger Lehm, mit } \\
\text { deformierten } \\
\text { Kalkschotterlinsen, } \\
\text { wenige alpine Gerölle. }\end{array}$ & $\begin{array}{l}\text { Kalkhaltiger, glimmer- } \\
\text { führender Silt, mit Feinsand- } \\
\text { fraktion aus Quarz und } \\
\text { lokalen Kalken. }\end{array}$ & $\begin{array}{l}\text { Solifluktionsablagerung aus } \\
\text { umgelagertem Löss, } \\
\text { Komponenten der Hochterrasse } \\
\text { und Kalkschotter. }\end{array}$ \\
\hline 6 & $\begin{array}{l}\text { Grauer sandiger Kies } \\
\text { mit frostverwitterten } \\
\text { Komponenten. }\end{array}$ & $\begin{array}{l}\text { (Keine mikromorphologische } \\
\text { Analyse). }\end{array}$ & $\begin{array}{l}\text { Rheinschotter. } \\
\text { Niederterrassenfeld A1. } \\
\text { Pedogen nicht überprägt. }\end{array}$ \\
\hline
\end{tabular}

Abb. 2a. Kaiseraugst "Im Sager“. Profildarstellung, Feldbeschrieb und Ergebnisse der mikromorphologischen Untersuchungen.

Legende:

\begin{tabular}{llll}
\hline & Ton \\
& Silt
\end{tabular}

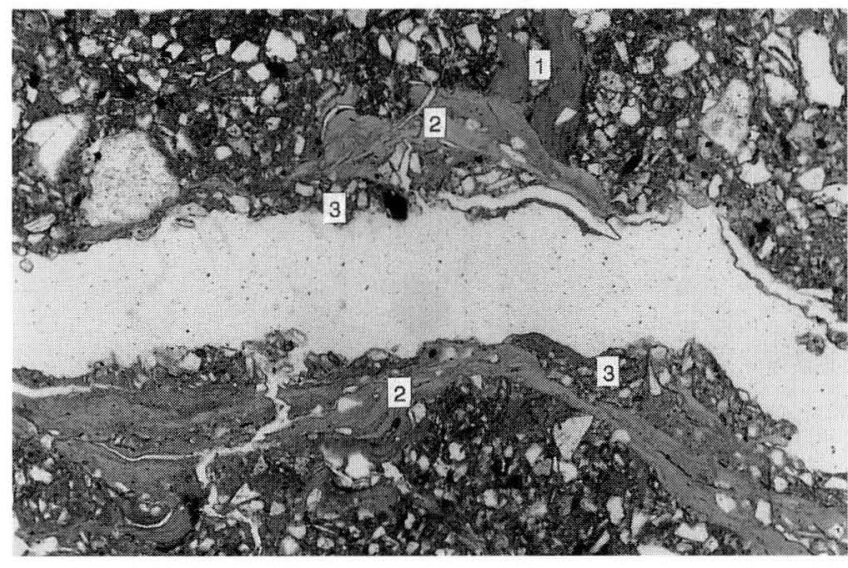

Abb. 2b. Kaiseraugst „Im Sager". Mikrophotographie von Horizont 4. Tonanreicherungshorizont einer Parabraunerde aus Schwemmlöss mit drei Illuvialphasen. Die ältesten, in die Bodenmatrix eingearbeiteten Tonbeläge (1) werden von jüngeren überdeckt (2, beidseits des zentralen Porenraums). Die letzte, in nachrömischer Zeit erfolgte Durchschlämmung des Bodens führte zu dunklen, siltig-sandigen Porenbelägen (3). - Bildbreite: 2,2 $\mathrm{mm}$, parallele Polarisationsfilter (PPL). 
Interpretation

Beobachtungen am Bodenprofil von Kaiseraugst „Im Sager" machen deutlich, dass nach der Aufschotterung des höchsten Niederterassenfeldes A1 - dem nach WitTMAnN $(1961,34)$ einzigen Akkumulationsniveau $^{4}$ - periglaziale Klimabedingungen geherrscht haben, was unter anderem durch die frostverwitterte Kiesoberfläche (Abb. 2a: Horizont 6) dokumentiert wird. Eine eigentliche Bodenbildung im Dach des Rheinschotters, die einen längeren Ablagerungsunterbruch belegen würde, liess sich dagegen nicht nachweisen.

Über den Rheinschottern folgt eine von der Hochterrasse abgespülte Solifluktionsablagerung, Horizont 5. Es handelt sich um sandigen Schwemmlöss, der Einschaltungen von grobkörnigem, lössführendem Solifluktionsschutt (Kalkschotter, mit Kristallin der Hochterrassenschotter angereichert) führen kann. In diesem Mischsubstrat aus Löss und Feinsand bildete sich in der Folge eine Parabraunerde, was zu einer Profildifferenzierung in die Horizonte 3 und 4 führte. Der Beginn der Bodenbildung lässt sich in diesem Profil zeitlich nicht genau bestimmen, die mikromorphologischen Untersuchungen zeigen jedoch, dass mehrere Toneinwaschungsphasen stattgefunden haben (Abb. $2 b)$. Zu den relativ gesehen ältesten Einschwemmungen in Horizont 4 gehören die rötlich gelben Tonbeläge (einer spätglazialen Bodenbildungsphase ?), die als Folge von Quellungs- und Schrump- fungsphänomenen in die Bodenmatrix eingearbeitet sind. In einer zweiten Phase sedimentierten in den Porenräumen siltig-tonige Ablagerungen von hellgelber Farbe (einer frühholozänen ${ }^{5}$ Bodenbildungsphase ?). Nach diesen beiden Illuvialphasen haben Staunässeereignisse - bedingt durch den wenig durchlässigen Horizont 4 - das Bodenprofil überprägt, was sich in der Bildung von Eisen- und Manganausfällungen an der Basis von Horizont 3 manifestierte. Diese Staunässeanzeiger werden von römischen Tonentnahmegruben durchschlagen, sind also mit Sicherheit schon in vorrömischer Zeit entstanden. Mikromorphologisch lässt sich eine letzte Durchschlämmung des Bodens mit einem siltig-organischen Feinsediment fassen. Da diese jüngsten Porenablagerungen auch in der Auffüllung der römischen Tonaufbereitungsgruben ${ }^{6}$ vorkommen, interpretieren wir sie als eine Folge der nachrömischen ackerbaulichen Nutzung des Gebietes.

\section{Augst „Kastelen“}

Geologisch-bodenkundliche Situation: Rötliche Parabraunerde aus Niederterrassenschottern (Teilfeld A1). Archäologischer Bezug: Die Parabraunerde wird von bronzezeitlichen Siedlungsspuren gekappt.

Koordinaten: 621'350/265'000

Höhe: $291 \mathrm{~m}$ ü. M.

Literatur: SCHWARZ (in Vorb.)

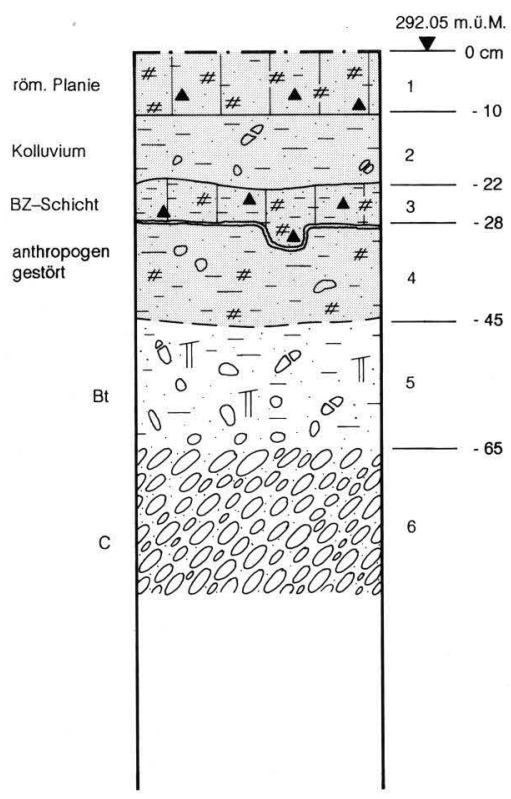

\section{Augst Kastelen}

\begin{tabular}{|c|l|l|l|}
\hline & Beschrieb & $\begin{array}{l}\text { Mikromorphologische } \\
\text { Merkmale }\end{array}$ & Interpretation \\
\hline 1 & $\begin{array}{l}\text { Holzkohlereicher, } \\
\text { sandiger Lehm. }\end{array}$ & $\begin{array}{l}\text { Sandiger Lehm mit viel } \\
\text { verbranntem Material. }\end{array}$ & Römische Planieschicht. \\
\hline 2 & $\begin{array}{l}\text { Hellbrauner, kiesig- } \\
\text { sandiger Lehm }\end{array}$ & $\begin{array}{l}\text { Heterogenes Sediment mit } \\
\text { Bodenaggregaten und Kies } \\
\text { aus Horizont 5. }\end{array}$ & Nachbronzezeitliches Kolluvium. \\
\hline 3 & $\begin{array}{l}\text { Hellbrauner, leicht } \\
\text { sandiger Lehm. }\end{array}$ & $\begin{array}{l}\text { Quarzsand mit oranger Ton- } \\
\text { matrix und Holzkohleflittern. } \\
\text { Verbrannter Lehm, gerötete } \\
\text { Steine und Koprolithen führend. }\end{array}$ & Bronzezeitliche Siedlungsspuren \\
\hline 4 & $\begin{array}{l}\text { Orangefarbener, sandig- } \\
\text { toniger Lehm, mit } \\
\text { unregelmässig verteiltem } \\
\text { Kies und hellbraunen } \\
\text { Lehmeinschlüssen. }\end{array}$ & $\begin{array}{l}\text { Bodenaggregate aus } \\
\text { Horizont 5 vermischt mit } \\
\text { holzkohlehaltigem Lehm. } \\
\text { Einschwemmungen von } \\
\text { organischemFeinmaterial. } \\
\text { Kompaktionsanzeiger. }\end{array}$ & $\begin{array}{l}\text { Durch menschliche Eingriffe } \\
\text { überprägter Oberboden. (Rodung } \\
\text { und Begehung.) }\end{array}$ \\
\hline 5 & $\begin{array}{l}\text { Orange-rötlicher, } \\
\text { lehmiger Kies mit } \\
\text { frostverwitterten } \\
\text { Komponenten. }\end{array}$ & $\begin{array}{l}\text { Starke Illuvation, als } \\
\text { feingeschichtete Tonab- } \\
\text { lagerungen in den Poren und } \\
\text { um Komponenten ausgebildet. }\end{array}$ & $\begin{array}{l}\text { Tonanreicherungshorizont einer } \\
\text { Rötlichen Parabraunerde aus } \\
\text { Rheinschottern. }\end{array}$ \\
\hline 6 & $\begin{array}{l}\text { Grauer sandiger Kies. } \\
\text { (Keine mikromorphologische } \\
\text { Analyse). }\end{array}$ & $\begin{array}{l}\text { Rheinschotter. } \\
\text { Niederterrassenfeld A1. }\end{array}$ \\
\hline
\end{tabular}

Abb. 3. Augst „Kastelen“. Profildarstellung, Feldbeschrieb und Ergebnisse der mikromorphologischen Untersuchungen (Legende s. Abb. 2a). 
Interpretation

Die in der nahe gelegenen Flur Kaiseraugst „Im Sager" beobachtete Schwemmlössdecke keilt gegen Norden hin aus (Abb. 1b) und ist auf dem Geländesporn von Augst „Kastelen“ nicht mehr vorhanden. Hier wurden die Niederterrassenschotter des Teilfeldes A1 von einer intensiv rötlich gefärbten Bodenbildung, einer Parabraunerde mit gut ausgebildeten, eisenoxidhaltigen Tonbelägen, erfasst (Abb. 3: Horizont 5). Dieser Schotterboden muss folglich das Äquivalent zur polygenetischen Bodenbildung aus Schwemmlöss von Kaiseraugst "Im Sager" darstellen. Auf dem spätestens seit der Bronzezeit sporadisch besiedelten Sporn von Augst „Kastelen" ist der Profilaufbau jedoch unvollständig: Prähistorische und römische Eingriffe führten zu einer Kappung im oberen Bereich des Bt-Horizontes. Ein Vergleich mit dem anthropogen nicht beein- flussten Profil von Muttenz „Kiesgrube Meyer-Spinnler" macht deutlich, dass auf Kastelen gegen $60 \mathrm{~cm}$ der Horizontabfolge, d. h. der Humushorizont, der darunterliegende Eluvialhorizont und partiell auch der Toneinwaschungshorizont, erodiert sind. Die archäologischen Befunde zeigen des weiteren, dass die Entwicklung der rötlichen Parabraunerde mit Sicherheit schon zur Bronzezeit abgeschlossen war.

\section{Muttenz „Kiesgrube Meyer-Spinnler“}

Geologisch-bodenkundliche Situation: Rötliche Parabraunerde aus Niederterrassenschottern (Teilfeld A2). Koordinaten: 616'900/264'175

Höhe: 281 m ü.M.

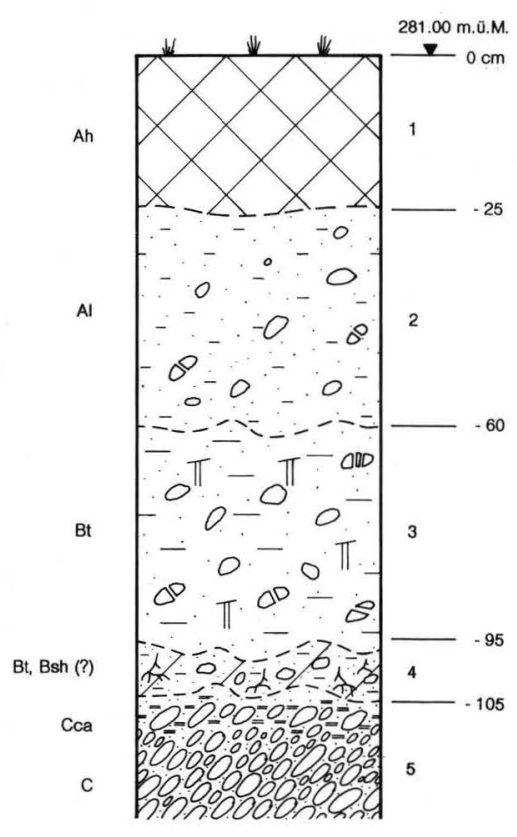

Muttenz, Kiesgrube Meyer-Spinnler

\begin{tabular}{|c|c|c|c|c|}
\hline & Beschrieb & $\begin{array}{l}\text { Mikrostruktur und } \\
\text { Komponenten }\end{array}$ & Pedogene Merkmale & Interpretation \\
\hline 1 & $\begin{array}{l}\text { Dunkelbrauner } \\
\text { sandiger Lehm } \\
\text { mit Kies. }\end{array}$ & $\begin{array}{l}\text { (Keine mikromorpho- } \\
\text { logische Analyse) }\end{array}$ & & $\begin{array}{l}\text { Humushorizont } \\
\text { (Waldstandort). }\end{array}$ \\
\hline 2 & $\begin{array}{l}\text { Gelbbrauner bis } \\
\text { oranger, schwach } \\
\text { lehmiger Sand } \\
\text { mit Fein- und } \\
\text { Grobkies. }\end{array}$ & $\begin{array}{l}\text { Kies mit siltig-feinsandiger } \\
\text { Matrix. Sandfraktion zu } \\
95 \% \text { aus Quarz bestehend, } \\
\text { daneben Feldspäte, ver- } \\
\text { witterte Glimmer und } \\
\text { Schwermineralien. Kiese } \\
\text { stark verwittert: poröse } \\
\text { Sandsteine und Mergel, } \\
\text { Granite mit braunen Oxida- } \\
\text { tionssäumen. Porosität: } \\
\text { 40\%, Kanal- und } \\
\text { Kammerstruktur. }\end{array}$ & $\begin{array}{l}\text { Ausgeprägte } \\
\text { Tonauswaschung. } \\
\text { Bioturbation, rezente } \\
\text { Durchwurzelung. }\end{array}$ & $\begin{array}{l}\text { Eluvialhorizont } \\
\text { einer Schotter- } \\
\text { parabraunerde. }\end{array}$ \\
\hline 3 & $\begin{array}{l}\text { Orange rötlicher } \\
\text { (5YR } 5 / 8 \text { bis } 2,5 \\
\text { YR } 5 / 8 \text { ), lehmiger } \\
\text { Sand mit Kies. } \\
\text { Viele } \\
\text { frostgesprengte } \\
\text { Gerölle (Abb. 4d). }\end{array}$ & $\begin{array}{l}\text { Sandig-kiesiger Lehm } \\
\text { mit vielen gestörten } \\
\text { Tontapeten (Abb 4b). } \\
\text { Komplexe Mikrostruktur: } \\
\text { Kammern, Kanäle und } \\
\text { Brückengefüge. Porosität: } \\
25-30 \% \text {. Chemisch } \\
\text { und physikalisch stark } \\
\text { verwitterte Komponenten. }\end{array}$ & $\begin{array}{l}\text { Starke Tonan- } \\
\text { reicherung. Jüngere } \\
\text { Phänomene: Biotur- } \\
\text { bation, intensive } \\
\text { Durchwurzelung, } \\
\text { Quellung/Schrump- } \\
\text { fung, schwache } \\
\text { Pseudovergleyung. }\end{array}$ & $\begin{array}{l}\text { Illuvialhorizont (Bt) } \\
\text { einer Parabraun- } \\
\text { erde aus Schottern }\end{array}$ \\
\hline 4 & $\begin{array}{l}\text { Orange brauner, } \\
\text { lehmiger Sand mit } \\
\text { Kies, stark } \\
\text { durchwurzelt. }\end{array}$ & $\begin{array}{l}\text { Kies mit sandig-lehmiger } \\
\text { Matrix. Einzelkorngefüge } \\
\text { und Brückenstruktur, } \\
\text { Porosität: } 30 \% \text {. }\end{array}$ & $\begin{array}{l}\text { Schwach ausge- } \\
\text { bildete Tonbeläge, } \\
\text { überdeckt von } \\
\text { bräunlichen, organi- } \\
\text { schen Umhüllungen. }\end{array}$ & $\begin{array}{l}\text { Basis des Bt- } \\
\text { Horizontes mit } \\
\text { Anreicherung } \\
\text { von organischem } \\
\text { Material. }\end{array}$ \\
\hline 5 & $\begin{array}{l}\text { Grauer, sandiger } \\
\text { Kies mit } \\
\text { Kalkausfällungen. } \\
\text { Schrägschichtung. }\end{array}$ & $\begin{array}{l}\text { Sandiger Kies, Einzelkorn- } \\
\text { gefüge, Porosität: } 40-45 \% \text {, } \\
\text { leicht verwitterte Kalke } \\
\text { und Granite. }\end{array}$ & $\begin{array}{l}\text { Kalkausfällungen und } \\
\text { vereinzelt braune } \\
\text { Umhüllungen um } \\
\text { Sandpartikel. }\end{array}$ & $\begin{array}{l}\text { Leicht verwitterte } \\
\text { Rheinschotter, } \\
\text { mit Kalkaus- } \\
\text { fällungen. Nieder- } \\
\text { terrassenfeld A2. }\end{array}$ \\
\hline
\end{tabular}

Abb. 4a. Muttenz "Kiesgrube Meyer-Spinnler". Profildarstellung, Feldbeschrieb und Ergebnisse der mikromorphologischen Untersuchungen (Legende s. Abb. 2a). 


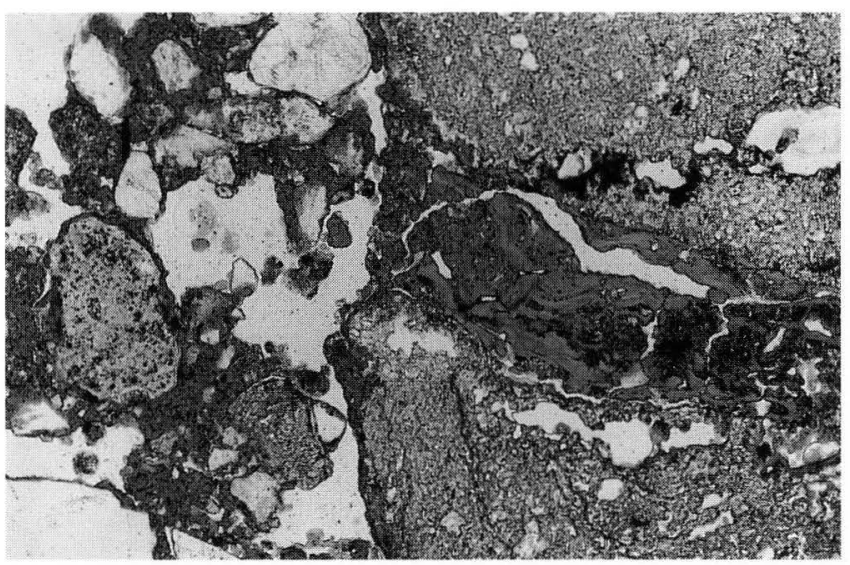

Abb. 4b. Muttenz "Kiesgrube Meyer-Spinnler". Mikrophotographie von Horizont 3. Rötlicher Tonanreicherungshorizont einer stark entwickelten Schotterparabraunerde. In der rechten Bildhälfte liegt ein verwittertes Silikatgeröll, in dessen Hohlräumen sich feinlaminierte Tonbeläge partiell erhalten haben. In der linken Bildhälfte erkennt man, wie die ursprünglich geschichtete Tonsubstanz durch Bioturbation sowie Quellung/Schrumpfung komplett aufgearbeitet und mit Quarzsand vermischt wurde. - Bildbreite: 2,2 mm, $P P L$.

\begin{tabular}{|l|l|l|l|l|}
\hline $\begin{array}{l}\text { Horizont } \\
\text { (Probentiefe) }\end{array}$ & Illit (\%) & Smectit (\%) & Chlorit (\%) & Kaolinit (\%) \\
\hline $2(-55 \mathrm{~cm})$ & $20-25$ & $10-15$ & $30-35$ & $30-35$ \\
\hline $3(-70 \mathrm{~cm})$ & $14-19$ & $9-14$ & $33-38$ & $33-38$ \\
\hline $3(-95 \mathrm{~cm})$ & $16-21$ & $26-31$ & $23-28$ & $25-30$ \\
\hline
\end{tabular}

Abb. 4c. Muttenz "Kiesgrube Meyer-Spinnler". Resultate der tonmineralogischen Untersuchungen.

Interpretation

Auf der von WitTMAnn (1961) als A2-Feld ausgeschiedenen Schotterebene lässt sich unter Waldstandort eine über $1 \mathrm{~m}$ mächtige Bodenbildung aus frostverwittertem Rheinkies beobachten (Abb. 4d). Der stark entwickelte Bt-Horizont ((Abb. 4a: Horizont 3) der rötlichen Parabraunerde ist mit Ausnahme seiner leicht hydromorphen Merkmale von demjenigen des Augster Profils nicht zu unterscheiden. Im Profil von Muttenz ist dieser Tonanreicherungshorizont knapp $50 \mathrm{~cm}$ mächtig und im Kontaktbereich mit den unterlagernden Rheinschottern durch organisches Material und Wurzelreste bräunlich verfärbt. Die mikromorphologischen Untersuchungen dokumentieren eine erhebliche Störung des Bodengefüges. So sind in Horizont 3 und 4 die feingeschichteten rötlichen Tonbeläge nur selten entlang der Porenräume oder um die Gerölle angeordnet, sondern meist regellos in der Bodenmatrix verteilt (Abb. 4b). Diese Umlagerungsprozesse sind auf Bioturbation, Wurzelwachstum sowie Quellung und Schrump- fung (Hydroturbation) unter wechselfeuchten Bedingungen zurückzuführen. Betrachtet man die Ergebnisse der semiquantitativen Analyse der Tonminerale aus Horizont 2 und 3, so fallen vor allem die hohen Smectitund Kaolinitgehalte auf (Abb. 4c) $)^{7}$. Falls es sich beim Kaolinit um eine pedogene Neubildung handelt, liegt ein weiteres Indiz vor, dass für stark verwitterte Bodenhorizonte spricht. Es sei in diesem Zusammenhang erwähnt, dass die mineralogische Zusammensetzung und Rotfärbung der Parabraunerde nicht allein mit dem hohen Bodenalter und den holozänen Klimabedingungen zu erklären sind. Die Bodenentwicklung dürfte in entscheidendem Masse auch durch das gut drainierte, mechanisch vorverwitterte Ausgangsgestein - das überdies einen hohen silikatischen Anteil enthält - mitbestimmt worden sein.

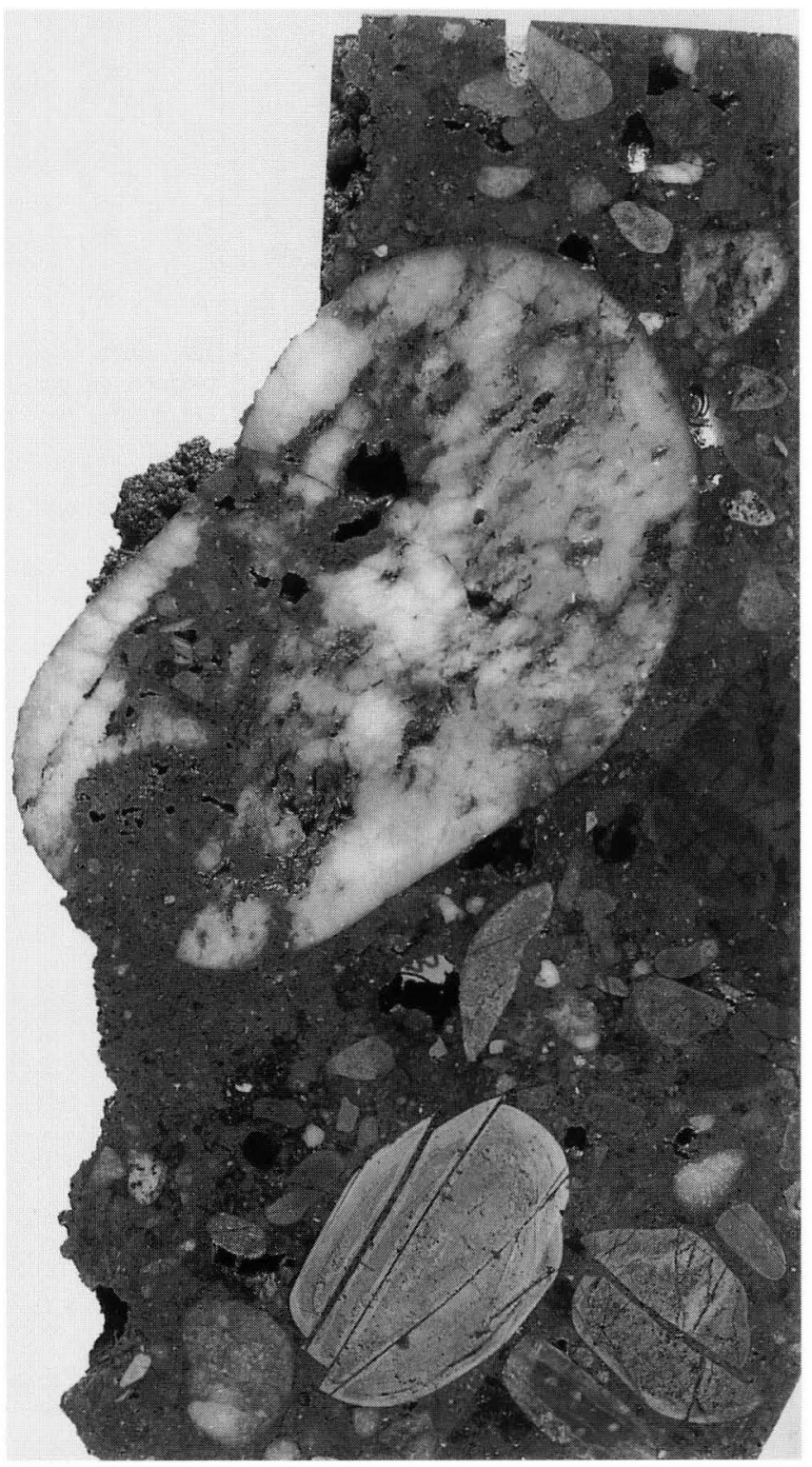

Abb. 4d. Muttenz "Kiesgrube Meyer-Spinnler". Mit Kunstharz gefestigte Bodenprobe aus dem Bt-Horizont. In der unteren Bildhälfte ist frostgesprengter Kies zu erkennen, darüber ein skelettartig verwittertes Granitgeröll mit eingeschwemmter rötlicher Tonsubstanz. - Höhe des Präparates: $14 \mathrm{~cm}$. 


\section{Basel-Münsterhügel „Rittergasse 4“}

Geologisch-bodenkundliche Situation: Verwitterter Decklehm über rötlicher Parabraunerde aus Niederterrassenschottern (Teilfeld A3).

Archäologischer Bezug: Prähistorische Funde im Decklehm, darüber folgt ein latènezeitlicher Wall.

Koordinaten: 611'600/267'200

Höhe: 270 m ü. M.

Literatur: Moor, Rentzel, Richner 1994; Rentzel 1997.

Interpretation

Auf dem Basler Münsterhügel, dem jüngsten Teilfeld A3 der höheren Niederterrasse, ist mit Horizont 4 (Abb. 5) ebenfalls eine rötliche Parabraunerde aus Rheinschottern belegt. Aufgrund der mikromorphologischen Befunde bestehen sehr grosse Ähnlichkeiten mit den
Bodenbildungen von Augst „Kastelen“ oder Muttenz „Kiesgrube Meyer-Spinnler". Allerdings ist auch auf dem Münsterhügel der Profilaufbau unvollständig, da über einem stellenweise weniger als $20 \mathrm{~cm}$ starken Bt-Horizont jüngere fluviatile Sande folgen, innerhalb derer sich eine weitere Bodenbildung abzeichnet. Zusätzlich weist dieses zweischichtige Bodenprofil in Horizont 2 diffuse Spuren einer prähistorischen Begehung und im obersten Abschnitt kolluvialen Charakter auf. Eine anthropogene Kappung des Bodenprofils, mit Abtrag des Humushorizontes und partiell des Eluvialhorizontes (Horizont 2), steht im Zusammenhang mit dem Bau des spätlatènezeitlichen Wall-Grabensystems. Durch diese menschlichen Eingriffe wurde im ersten vorchristlichen Jahrhundert die natürliche Bodenentwicklung abrupt unterbrochen und der damalige Zustand durch die künstlichen Überschüttungen konserviert.

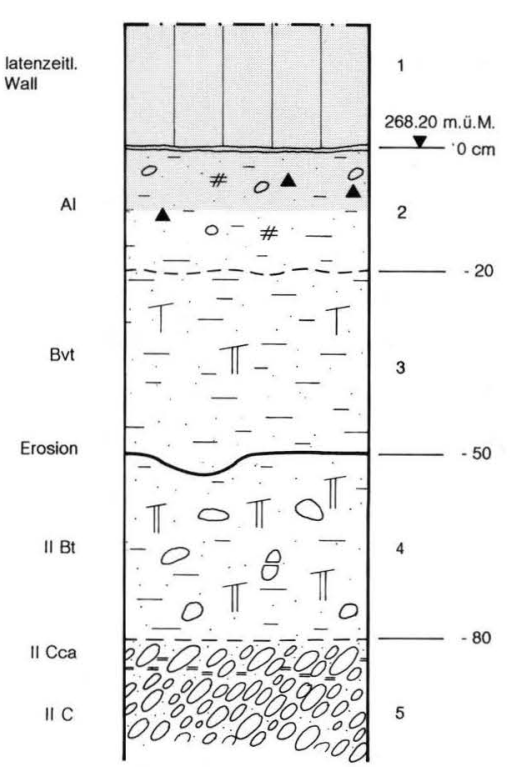

Basel-Münsterhügel, Rittergasse 4

\begin{tabular}{|c|c|c|c|c|}
\hline & Beschrieb & $\begin{array}{l}\text { Komponenten und } \\
\text { Mikrostruktur }\end{array}$ & Pedogene Merkmale & Interpretation \\
\hline 1 & $\begin{array}{l}\text { Brauner, } \\
\text { sandiger Lehm. }\end{array}$ & $\begin{array}{l}\text { Sediment mit Aggregaten } \\
\text { aus Horizont } 2 \text { bis } 5 .\end{array}$ & Leichte Hydromorphie. & $\begin{array}{l}\text { Latènezeitliche } \\
\text { Wallschüttung. }\end{array}$ \\
\hline 2 & $\begin{array}{l}\text { Hellbrauner bis } \\
\text { beiger, sandiger } \\
\text { Lehm mit wenig } \\
\text { Kies. }\end{array}$ & $\begin{array}{l}\text { Eckiger Quarzsand mit } \\
\text { unregelmässig verteilten } \\
\text { Kieskomponenten. } \\
\text { Kanalstruktur. Holzkohle- } \\
\text { partikel und seltene } \\
\text { Silexsplitter. }\end{array}$ & $\begin{array}{l}\text { Tonauswaschung. } \\
\text { Bioturbation. } \\
\text { Gebänderte Eisen- } \\
\text { und } \\
\text { Mangankonkretionen. }\end{array}$ & $\begin{array}{l}\text { Eluvialhorizont aus } \\
\text { fluviatilen Sanden, } \\
\text { genetisch zu } \\
\text { Horizont } 3 \text { gehörig. } \\
\text { Spuren prä- } \\
\text { historischer Be- } \\
\text { gehungen.Ober- } \\
\text { flächlich leicht } \\
\text { verlagert. }\end{array}$ \\
\hline 3 & $\begin{array}{l}\text { Brauner, } \\
\text { kompakter } \\
\text { sandiger Lehm. }\end{array}$ & $\begin{array}{l}\text { Eckiger Quarzsand mit } \\
\text { brauner Tonmatrix. } \\
\text { Massive Struktur. Entkalkt. } \\
\text { Wenige Holzkohleflitter. }\end{array}$ & $\begin{array}{l}\text { Diffuse } \\
\text { Tonanreicherung in } \\
\text { der Grundmasse. } \\
\text { Netzstreifig } \\
\text { ausgerichtete } \\
\text { Tonmatrix. }\end{array}$ & $\begin{array}{l}\text { Bodenhorizont mit } \\
\text { schwacher Tonan- } \\
\text { reicherung (Bvt), } \\
\text { aus fluviatilen } \\
\text { Sanden entstanden. } \\
\text { Erosionsdiskordanz } \\
\text { gegen Horizont } 4 . \\
\text { Durch Staunässe } \\
\text { überprägt. }\end{array}$ \\
\hline 4 & $\begin{array}{l}\text { Rötlicher (5YR } \\
5 / 8 \text { ), lehmiger } \\
\text { Kies mit } \\
\text { frostverwitterten } \\
\text { Geröllen. }\end{array}$ & $\begin{array}{l}\text { Eckiger Quarzsand und } \\
\text { Gerölle in toniger Matrix. } \\
\text { Stark verwitterte } \\
\text { Komponenten und } \\
\text { vollständig entkalktes } \\
\text { Skelett. Aggregatgefüge. } \\
\text { Konzentrische } \\
\text { Eisenkonkretionen. }\end{array}$ & $\begin{array}{l}\text { Bodenmatrix besteht } \\
\text { aus streifig } \\
\text { ausgerichteten } \\
\text { Tonbelägen } \\
\text { (Quellung/ } \\
\text { Schrumpfung). Siltig- } \\
\text { organische } \\
\text { Einschwemmungen in } \\
\text { Porenräumen werden } \\
\text { von Eisenoxiden } \\
\text { überdeckt. }\end{array}$ & $\begin{array}{l}\text { Bodenhorizont } \\
\text { (Illuvialhorizont), der } \\
\text { folgende Ereignisse } \\
\text { aufgezeichnet hat: } \\
\text { 1. Frostverwitterung } \\
\text { der Schotter. } \\
\text { 2. Bildung einer } \\
\text { Parabraunerde. } \\
\text { 3. Zerstörung des } \\
\text { Bodengefüges durch } \\
\text { Quellung/Schrump- } \\
\text { fung, Bioturbation } \\
\text { und Wurzel- } \\
\text { wachstum. } \\
\text { 4. Jüngere } \\
\text { Durchschlämmung } \\
\text { und Hydromorphie. }\end{array}$ \\
\hline 5 & $\begin{array}{l}\text { Grauer, } \\
\text { sandiger } \\
\text { Rheinschotter. }\end{array}$ & $\begin{array}{l}\text { (Keine mikromorpho- } \\
\text { logischen Analysen.) }\end{array}$ & $\begin{array}{l}\text { Kalkausblühungen an } \\
\text { den Geröllunterseiten. }\end{array}$ & $\begin{array}{l}\text { Rheinschotter mit } \\
\text { Kalkausfällungs- } \\
\text { horizont. Nieder- } \\
\text { terrassenfeld A3. }\end{array}$ \\
\hline
\end{tabular}

Abb. 5. Basel-Münsterhügel „Rittergasse 4". Profildarstellung, Feldbeschrieb und Ergebnisse der mikromorphologischen Untersuchungen (Legende s. Abb. 2a). 


\section{Basel „Bäumleingasse 14“}

Geologisch-bodenkundliche Situation: Braunerde (pseudovergleyt) aus spätglazialen Altarmablagerungen über Niederterrassenschottern (Teilfeld A3).

Archäologischer Bezug: Römische Strukturen durchschlagen die Braunerde.

Koordinaten: 611'550/267'100

Höhe: 266 m ü. M.
Interpretation

In Bezug auf die Datierung des Niederterrassenfeldes A3 nimmt das Profil von Basel „Bäumleingasse 14 " eine zentrale Stellung ein. Die Schotterebene des Münsterhügels beschreibt südöstlich der Bäumleingasse eine leichte Senke, die von spätglazialen Altarmablagerungen (Abb. 6a: Horizont 3 und 4) ausgefüllt wird ${ }^{8}$. Da die Oberfläche der Rheinschotter weder physikalische noch chemische Verwitterungsphänomene zeigt, dürfte kein längerer Hiatus zwischen der fluviatilen Überformung der Rheinschotter und der

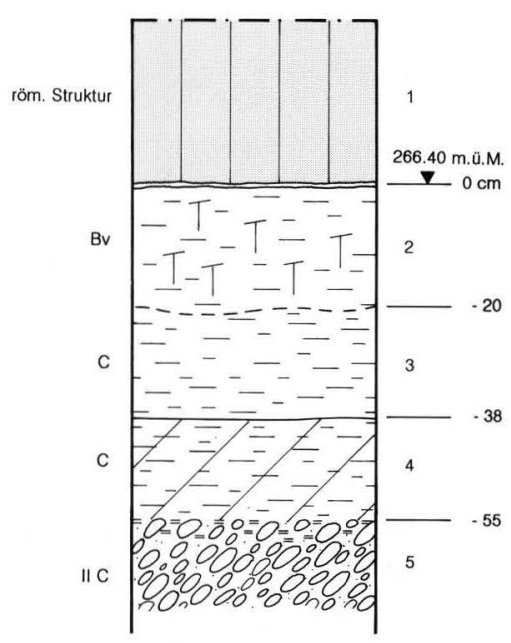

Basel Bäumleingasse 14

\begin{tabular}{|c|l|l|l|}
\hline & Beschrieb & $\begin{array}{l}\text { Mikromorphologische } \\
\text { Merkmale }\end{array}$ & Interpretation, Datierung \\
\hline 1 & $\begin{array}{l}\text { Schwarzbrauner, siltig- } \\
\text { toniger Lehm, mit viel } \\
\text { Holzkohle. Hüttenlehm. }\end{array}$ & $\begin{array}{l}\text { Bioturbiertes Sediment, } \\
\text { Gemisch aus Horizont 2 und 3. } \\
\text { Gebrannter Lehm, Holzkohle- } \\
\text { flitter und Keramik. }\end{array}$ & $\begin{array}{l}\text { Römische Planieschicht über } \\
\text { einem Kolluvium mit } \\
\text { prähistorischen Funden. }\end{array}$ \\
\hline 2 & Brauner toniger Silt. & $\begin{array}{l}\text { Sandiger, kalkfreier Lehm. } \\
\text { Tonige Matrix mit } \\
\text { netzstreifigem Gefüge und } \\
\text { Eisenoxiden (Hydromorphie) } \\
\text { (Abb. 6b). }\end{array}$ & $\begin{array}{l}\text { Verwitterungshorizont einer } \\
\text { pseudovergleyten Braunerde } \\
\text { aus Altarmsedimenten. }\end{array}$ \\
\hline 3 & $\begin{array}{l}\text { Gelbbrauner, schwach } \\
\text { toniger Silt. }\end{array}$ & $\begin{array}{l}\text { (Keine mikromorphologische } \\
\text { Analyse). }\end{array}$ & $\begin{array}{l}\text { Spätglaziale Altarmablagerungen } \\
\text { (Alleröd oder Dryas III). }\end{array}$ \\
\hline 4 & $\begin{array}{l}\text { Dunkelbrauner, siltig } \\
\text { toniger Lehm mit } \\
\text { weissen, kalkhaltigen } \\
\text { Zonen. }\end{array}$ & $\begin{array}{l}\text { (Keine mikromorphologische } \\
\text { Analyse). }\end{array}$ & $\begin{array}{l}\text { Spätglaziale Altarmablagerungen } \\
\text { (Bölling-Interstadial). }\end{array}$ \\
\hline 5 & $\begin{array}{l}\text { Schräggeschichtete } \\
\text { Rheinschotter, von } \\
\text { kreidigen } \\
\text { Kalkablagerungen } \\
\text { bedeckt }\end{array}$ & $\begin{array}{l}\text { (Keine mikromorphologische } \\
\text { Analyse). }\end{array}$ & $\begin{array}{l}\text { Rheinschotter. } \\
\text { Niederterrassenfeld A3. } \\
\text { Pedogen nicht überprägt. }\end{array}$ \\
\hline
\end{tabular}

Abb. 6a. Basel „Bäumleingasse 14“. Profildarstellung, Feldbeschrieb und Ergebnisse der mikromorphologischen Untersuchungen (Legende s. Abb. 2a).

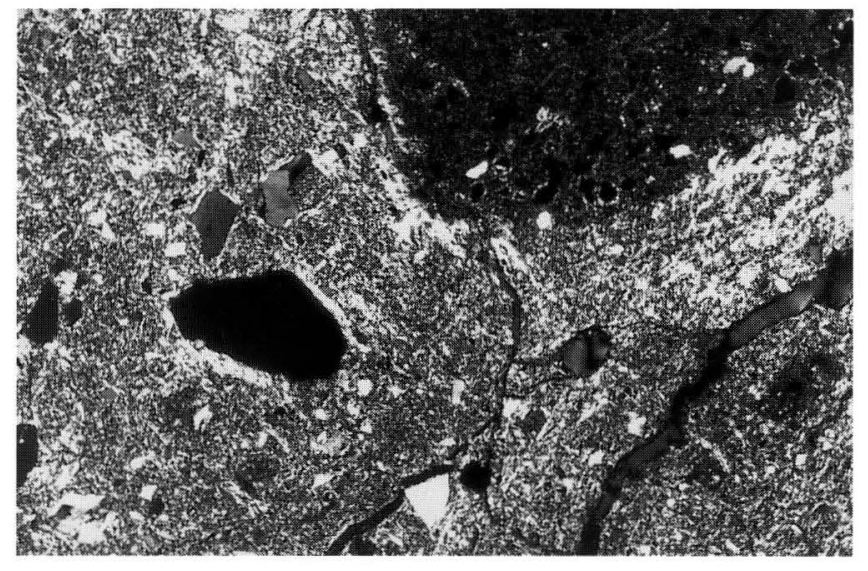

Abb. 6b. Basel „Bäumleingasse 14“. Mikrophotographie von Horizont 2. Verwitterungshorizont (Bv) einer Braunerde aus spätglazialen Tonen. Die netzstreifig ausgerichteten, hellen Tonminerale weisen auf Staunässeüberprägung (Hydromorphie) hin. - Bildbreite: 2,2 mm, gekreuzte Polarisationsfilter (XPL).
Ablagerung der feinkörnigen Stillwassersedimente gelegen haben. Daraus lässt sich folgern, dass die Bildung des Niederterrassenfeldes A3 spätestens im Bölling-Interstadial abgeschlossen war. Die von WITTMANN $(1961,41)$ vermutete mittelwürmzeitliche Entstehung des A3-Niederterrassenfeldes ist aufgrund der hier fehlenden Verwitterungsdecke ${ }^{9}$ wenig wahrscheinlich, da die palynologischen Untersuchungen von Horizont 4 indirekt für ein jungwürmzeitliches Alter der Schotter sprechen. Wie der Stratigraphie weiter zu entnehmen ist, fehlt hier die auf dem nahen Münsterhügel ebenfalls nachgewiesene rötliche Schotterparabraunerde. In der Bäumleingasse setzte die Pedogenese erst in den endglazialen Stillwassersedimenten (Horizont 2 und 3) ein und führte zu einer Braunerde (Abb. 6b), die keine vergleichbaren pedogenen Merkmale wie die rötlichen Schotterböden der A-Felder aufweist. Obschon die beiden Ausgangssubstrate (Schotter/tonige Altarmsedimente) sehr unterschiedlich sind und sich deshalb im Laufe der Zeit auch unterschiedliche Boden- 
typen entwickelt haben, dürften die rötlichen Schotterböden ein höheres Bodenalter aufweisen, da ihre Verwitterung nachweislich spätestens im Bölling-Interstadial begonnen hat. Auch an der Bäumleingasse ist die Pedogenese in den fluviatilen Ablagerungen schon in vorrömischer Zeit abgeschlossen: In mehreren Aufschlüssen werden die natürlich entstandenen Sedimente (bis zu Horizont 3) von einem lehmigem Kolluvium überlagert, das - unterhalb der römischen Planieschichten - prähistorische Funde enthalten kann.

\section{Kaiseraugst „Kastell, Jakobli-Haus“}

Geologisch-bodenkundliche Situation: Schwach entwickelte Parabraunerde aus Hochflutsanden über Niederterrassenschottern (Teilfeld B3).

Archäologischer Bezug: Die Parabraunerde wird von römischen Strukturen gekappt.

Koordinaten: 621'375/265'575

Höhe: $265 \mathrm{~m}$ ü. M.

Literatur: MüLLER 1995, $71 \mathrm{ff}$.

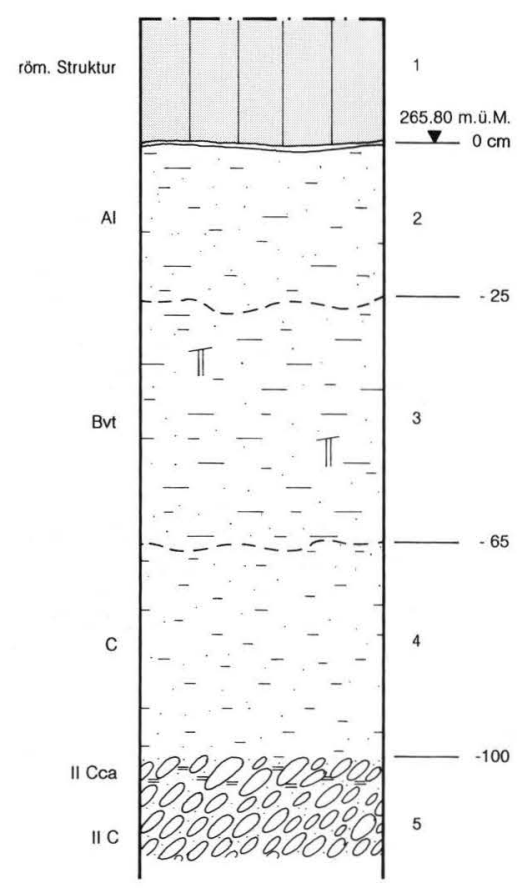

Kaiseraugst Kastell

\begin{tabular}{|c|c|c|c|}
\hline & Beschrieb & $\begin{array}{l}\text { Mikromorphologische } \\
\text { Merkmale }\end{array}$ & Interpretation \\
\hline 1 & $\begin{array}{l}\text { Sandiger Lehm mit } \\
\text { Bruchsteinen und Mörtel. }\end{array}$ & $\begin{array}{l}\text { Kompaktiertes Sediment mit } \\
\text { Bausteinsplittern und } \\
\text { Mörtelniveau. }\end{array}$ & Römische Struktur, Bauhorizont \\
\hline 2 & $\begin{array}{l}\text { Beiger, leicht lehmiger } \\
\text { Feinsand. }\end{array}$ & Tonverarmung. & Tonauswaschungshorizont. \\
\hline 3 & $\begin{array}{l}\text { Brauner, lehmiger } \\
\text { Feinsand. Kompakt. } \\
\text { Eisenausfällungen. }\end{array}$ & $\begin{array}{l}\text { Feinsand mit korrodierten } \\
\text { Kalkpartikeln. Dünne, } \\
\text { hellbraune Tonbeläge in den } \\
\text { Poren. Leichte Hydromorphie } \\
\text { (netzstreifiges Gefüge). }\end{array}$ & $\begin{array}{l}\text { Schwach entwickelter } \\
\text { Toneinwaschungshorizont einer } \\
\text { Parabraunerde aus } \\
\text { Hochflutsanden. }\end{array}$ \\
\hline 4 & Grauer siltiger Feinsand. & Kalkhaltiger Feinsand. & $\begin{array}{l}\text { Unverwitterte } \\
\text { Hochflutablagerung des Rheins. }\end{array}$ \\
\hline 5 & $\begin{array}{l}\text { Grauer sandiger Kies mit } \\
\text { Kalkausfällungen an } \\
\text { Geröllunterseiten. }\end{array}$ & $\begin{array}{l}\text { (Keine mikromorphologische } \\
\text { Analyse). }\end{array}$ & $\begin{array}{l}\text { Rheinschotter mit } \\
\text { Kalkausfällungshorizont. } \\
\text { Niederterrassenfeld B3. }\end{array}$ \\
\hline
\end{tabular}

Abb. 7a. Kaiseraugst „Kastell, Jakoblihaus“. Profildarstellung, Feldbeschrieb und Ergebnisse der mikromorphologischen Untersuchungen (Legende s. Abb. 2a).

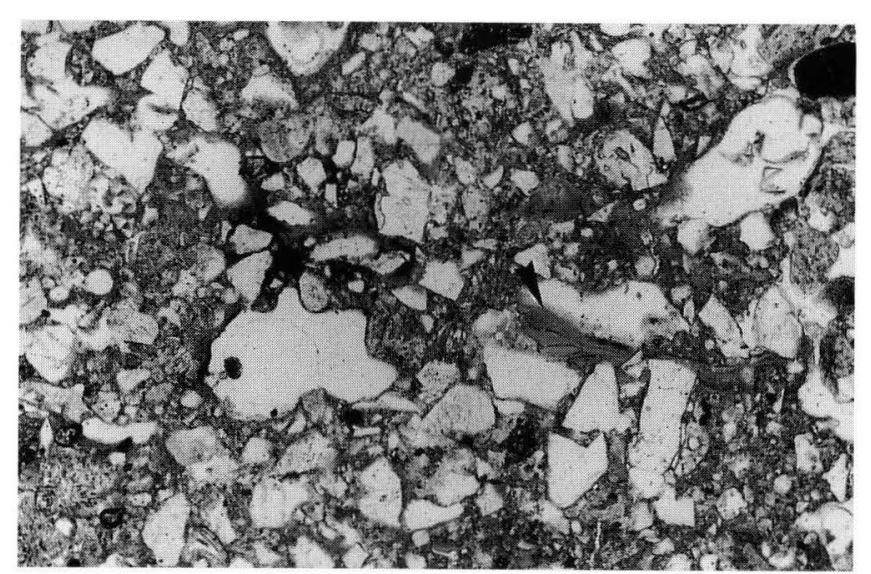

Abb. 7b. Kaiseraugst „Kastell, Jakoblihaus“. Mikrophotographie von Horizont 3. Schwach entwickelter, brauner Tonanreicherungshorizont (Bvt) einer Parabraunerde aus Hochflutsanden des Rheins. In den Poren des noch kalkhaltigen (!) Verwitterungshorizontes finden sich dünne Tonbeläge (Pfeil), die mit Eisenoxiden belegt sind. - Bildbreite: 2,2 mm, PPL.
Interpretation

In mehreren Aufschlüssen inner- und ausserhalb des Kaiseraugster Kastells werden die Niederterrassenschotter des tieferen B3-Feldes von grauen Feinsanden überdeckt. Letztere gehen in eine Parabraunerde mit einem braungefärbten (10YR 5/6, yellowish brown) Tonanreicherungshorizont über, der sich klar von den rötlichen Bt-Horizonten der Bodenbildungen auf AFeldern abhebt. Im Gegensatz zu den weiter oben geschilderten rötlichen Schotterböden handelt es sich bei dieser bräunlichen Bodenbildung aus wohl holozänen Hochflutsanden um ein jüngeres, deutlich schwächer entwickeltes Stadium. Man erkennt dies unter anderem an den diskreten, gelblich braunen Tonbelägen in Horizont 3, der seinerseits noch nicht komplett entkalkt ist (Abb. 7b). Im selben Bodenhorizont erfolgte nach der einphasigen Toneinschwemmung eine leichte hydromorphe Überprägung, die zu Eisen- und Manganausscheidungen sowie netzstreifiger Ausrichtung der Tonsubstanz führte. Die pedogene Verwitterung der Hochflutsande muss aufgrund stratigraphischer Evidenzen spätestens in römischer Zeit abgeschlossen gewesen sein, da die natürliche Bodenentwicklung mit dem Bau des Kastells im vierten Jahrhundert $\mathrm{n}$. Chr. beendet war. 


\section{Basel-Gasfabrik „Fabrikstrasse 5“}

Geologisch-bodenkundliche Situation: Schwach entwickelte Parabraunerde aus holozänen Hochflutsanden über Niederterrassenschottern (Teilfeld B3).

Archäologischer Bezug: Die Parabraunerde wird von latènezeitlichen Strukturen durchschlagen.

Koordinaten: 610'625/269'025 ${ }^{10}$

Höhe: 255 m ü. M.

Literatur: JUD/SPICHTIG 1992
Interpretation

Gleich wie der oben vorgestellte Aufschluss Kaiseraugst "Kastell“ befindet sich auch die archäologische Fundstelle Basel-Gasfabrik auf dem tiefsten Niederterrassenfeld B3 (WITTMANN 1961). Diese Ebene wird grossflächig von feinkörnigen Hochflutsanden bedeckt, die in den vom Rheinschotter vorgezeichneten Depressionen eine Mächtigkeit von gegen $2 \mathrm{~m}$ erreichen können ${ }^{11}$. Malakologische Analysen in den Ausgrabungen an der Fabrikstrasse 5 zeigen, dass hier die Sedi-

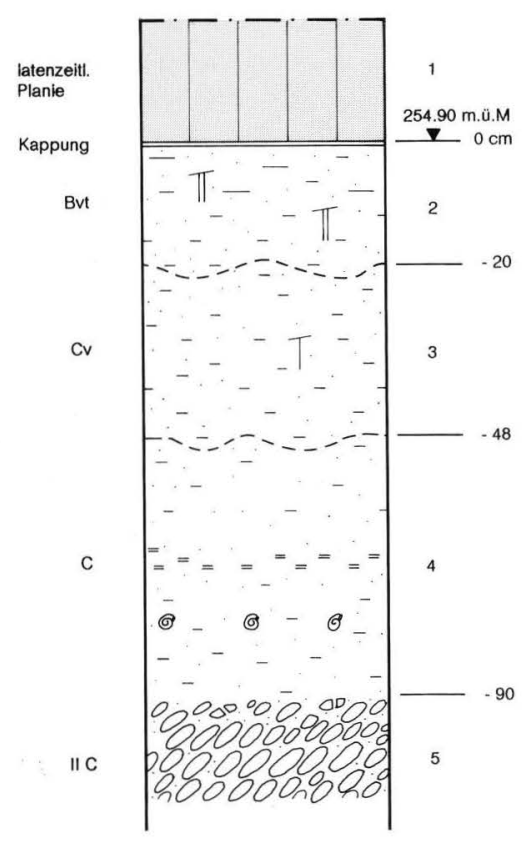

Basel-Gasfabrik, Fabrikstr. 5

\begin{tabular}{|c|c|c|c|}
\hline & Beschrieb & $\begin{array}{l}\text { Mikromorphologische } \\
\text { Merkmale }\end{array}$ & Interpretation \\
\hline 1 & $\begin{array}{l}\text { Brauner sandiger Lehm } \\
\text { mit Kies. Latènezeitliche } \\
\text { Funde. }\end{array}$ & $\begin{array}{l}\text { Feinsandiges Sediment mit } \\
\text { Bodenmaterial aus Horizont } \\
2 \text { bis } 5 . \text { Reich an fein verteilter } \\
\text { Holzkohle,organischem } \\
\text { Material und Koprolithen. }\end{array}$ & Latènezeitliche Planie. \\
\hline 2 & $\begin{array}{l}\text { Gelbbrauner, } \\
\text { feinsandiger Lehm. }\end{array}$ & $\begin{array}{l}\text { Lehmiger Feinsand mit } \\
\text { korrodierten Kalkpartikeln. } \\
\text { Dünne, hellbraune } \\
\text { Tonbeläge in den Poren. } \\
\text { Leichte Hydromorphie. }\end{array}$ & $\begin{array}{l}\text { Schwach entwickelter } \\
\text { Toneinwaschungshorizont } \\
\text { einer Parabraunerde. }\end{array}$ \\
\hline 3 & Gelber siltiger Feinsand & $\begin{array}{l}\text { Fluviatiler Feinsand mit } \\
\text { unverwitterten und korrodierten } \\
\text { Kalken. Beginnende } \\
\text { Verbraunung. }\end{array}$ & Leicht verwitterter Hochflutsand. \\
\hline 4 & Grauer siltiger Feinsand. & $\begin{array}{l}\text { Kalkhaltiger, unverwitterter } \\
\text { Feinsand mit einer } \\
\text { Molluskenfauna aus dem } \\
\text { Atlantikum. }\end{array}$ & $\begin{array}{l}\text { Holozäne Hochflutablagerung des } \\
\text { Rheins. }\end{array}$ \\
\hline 5 & $\begin{array}{l}\text { Grauer sandiger Kies } \\
\text { mit wenigen } \\
\text { frostverwitterten } \\
\text { Komponenten. } \\
\text { Schrägschichtung. }\end{array}$ & $\begin{array}{l}\text { Kalkhaltiger Rheinschotter, } \\
\text { Einzelkorngefüge, leichte } \\
\text { Frostverwitterung. }\end{array}$ & $\begin{array}{l}\text { Rheinschotter, pedogen nicht } \\
\text { überprägt. } \\
\text { Niederterrassenfeld B3. }\end{array}$ \\
\hline
\end{tabular}

Abb. 8a. Basel-Gasfabrik „Fabrikstrasse 5“. Profildarstellung, Feldbeschrieb und Ergebnisse der mikromorphologischen Untersuchungen (Legende s. Abb. 2a).

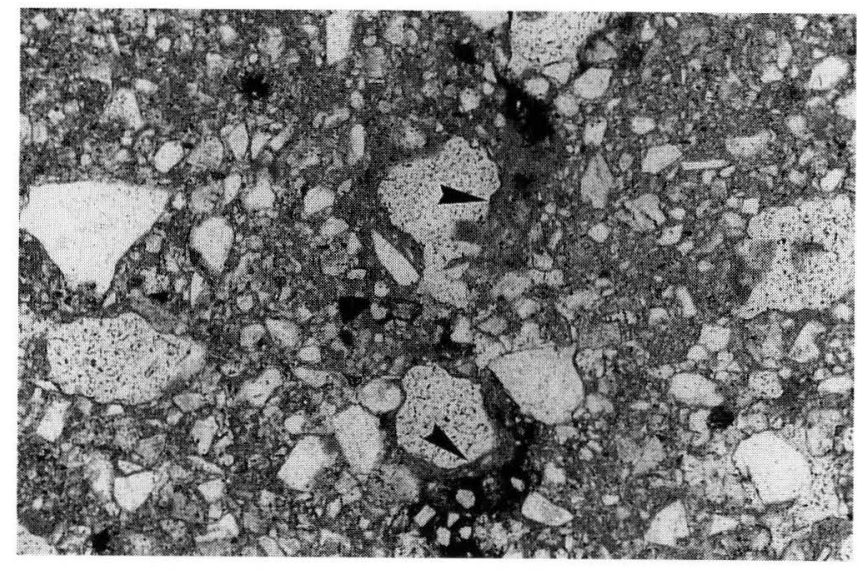

Abb. 8b. Basel-Gasfabrik „Voltastr. 30/3“. Mikrophotographie des Bvt-Horizontes. Schwach ausgeprägter Tonanreicherungshorizont einer Parabraunerde aus atlantischen Hochflutsanden mit hellbraunen Tonbelägen (Pfeile) in den Porenräumen. - Bildbreite: 2,2 mm, PPL. mentation der Hochflutsande im Atlantikum begann ${ }^{12}$. Über die chronostratigraphische Stellung der unterlagernden Rheinschotter lassen sich dagegen keine verlässlichen Aussagen machen. Es ist lediglich festzuhalten, dass bisher in keinem der nahezu über das ganze Siedlungsareal ${ }^{13}$ verteilten modernen Aufschlüsse die Reste eines unter Hochflutsanden begrabenen Schotterbodens gefasst wurden. Stellenweise sind in den Rheinschottersenken flachgründig frostverwitterte Kiesoberflächen sichtbar, nie jedoch fossile Humusbildungen oder gar Reste von Mineralbodenhorizonten. Die fluviatile Überformung, die zur Herausbildung der B3-Terrasse geführt hat, scheint daher nicht allzu lange vor der Ablagerung der atlantischen Hochflutsedimente stattgefunden zu haben. In diesen grauen Feinsanden bildete sich bis zur jüngeren Eisenzeit eine schwach entwickelte Parabraunerde mit pedogenen Merkmalen, wie sie auch in den Aufschlüssen von Kaiseraugst „Kastell" vorgefunden wurde (Abb. 8b). 


\section{Schlussfolgerungen}

Auf den drei höheren Niederterrassenfeldern (A-Felder) finden sich Verwitterungsdecken in Form rotgefärbter Schotterparabraunerden, die einen sehr ähnlichen Entwicklungsstand aufweisen. Eine Gegenüberstellung mit der Parabraunerde aus Schwemmlöss von Kaiseraugst "Im Sager" zeigt, dass auch bei den Schottern von einer komplexen (polygenetischen) Bodenbildung auszugehen ist. Die palynologische Datierung der Altarmsedimente an der Bäumleingasse deutet auf ein jungwürmzeitliches Alter des A3-Feldes, so dass auf diesem Schotterniveau die Bodenentwicklung mit grösster Wahrscheinlichkeit bereits ab dem Bölling-Interstadial eingesetzt hat ${ }^{14}$ (Abb. 9). Aufgrund der mikromorphologischen Untersuchungen ist auch für die beiden höheren A1- und A2-Felder ein jungwürmzeitlicher Datierungsansatz denkbar, liegen doch weder stratigraphische noch pedologische Anhaltspunkte für das von WITTMANN (1961) postulierte höhere Alter (Mittel- bzw. Frühwürm) dieser Niederterrassenfelder vor. Ein regionaler Vergleich mit der gut datierten fluviatilen Sequenz von Les Montoyes (JU) zeigt, dass im Delsberger Becken die Bildung fluvio-glazialer Schotter ebenfalls im Laufe des Bölling-Interstadials abgeschlossen war und von einer bis ins Atlantikum dauernden Torfsedimentation abgelöst wurde (Guélat 1993, 44). Derselbe Autor folgert, dass die in Westeuropa mehrfach nachgewiesene Wende in der fluviatilen Dynamik ${ }^{15}$ - der Wechsel von kaltzeitlichen Schottern eines verzweigten Flusssystems (braided river) zu feinkörnigen Ablagerungen eines mäandrierenden Gewässers - im Nordwestschweizer Jura zu Beginn des Spätglazials stattgefunden hat. In die gleiche Richtung weisen auch die palynologisch datierten Befunde von Basel „Bäumleingasse 14". Innerhalb der Basler Terrassenabfolge liegen für die nächsttieferen, durch fluviatile Erosion entstandenen B1- und B2-Terrassen mangels guter Aufschlüsse vorderhand keine chronologischen Anhaltspunkte vor. Möglicherweise dokumentieren sie einen Teil der frühholozänen Flussgeschichte. Eine nächste chronologisch fassbare Ablagerung stellen erst wieder die Hochflutsande des B3-Feldes von Basel-Gasfabrik dar. Deren Sedimentation setzte mit unbekannter Dauer ab dem Atlantikum ein, was im Gegensatz zum bisherigen spätglazialen Datierungsansatz von WITTMANN (1961) steht. Auch die schwach entwickelten Bodenbildungen des B3-Feldes unterscheiden sich in jeder Hinsicht markant von denjenigen der A-Felder und sind ein zusätzliches Indiz für dessen niedrigeres Alter.

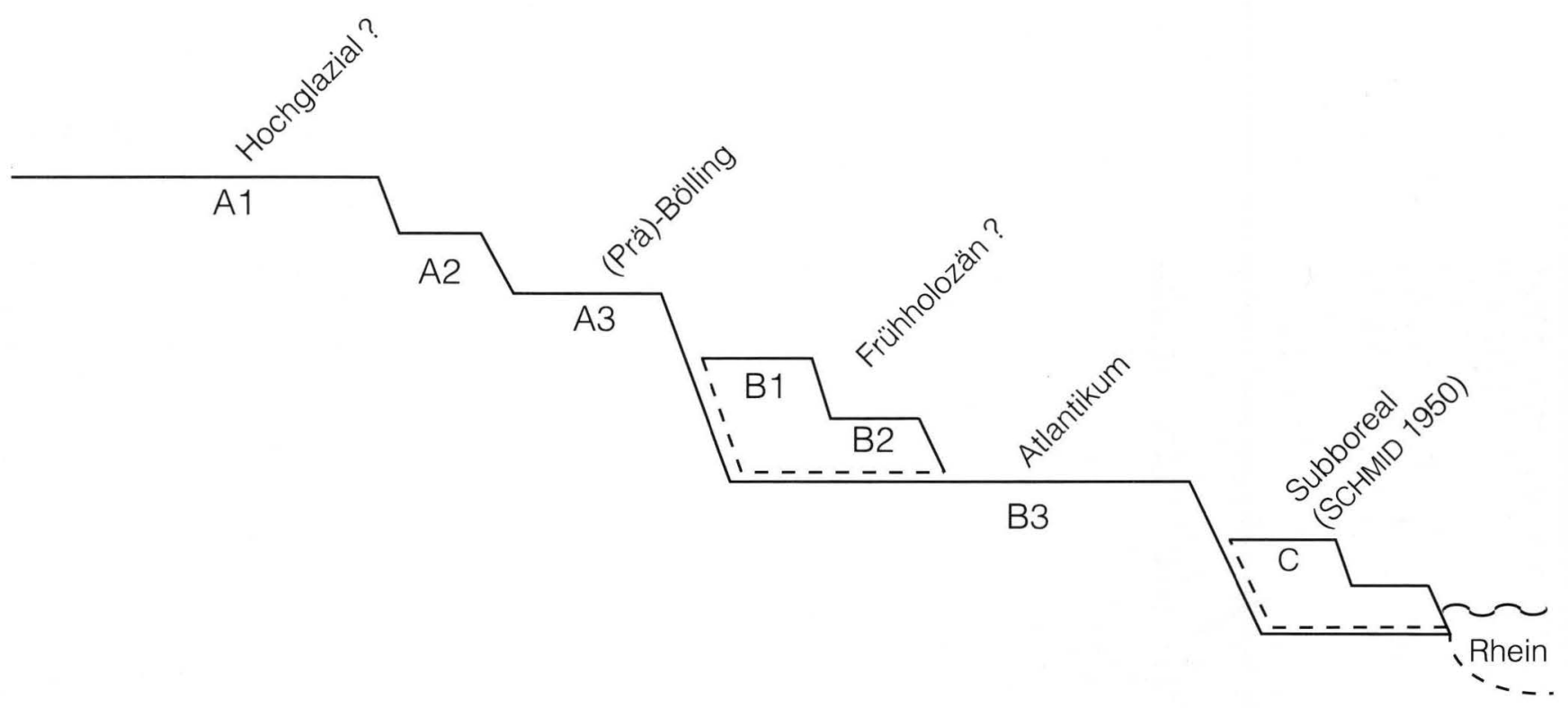

Abb. 9. Versuch einer chronologischen Einordnung der Niederterrassenfelder bei Basel aufgrund pedostratigraphischer, palynologischer, malakologischer und archäologischer Befunde. Verlässliche Altersangaben-die sich auf die letztmalige fluviatile Überformung einer Terrasse beziehen - liegen für das C-Feld (SCHMID 1950), das B3-Feld sowie das A3-Feld vor. Nach WITTMAnN (1961) stellt einzig das A1-Feld ein Akkumulationsniveau (hochglaziale Aufschotterung?) dar, alle tieferen Felder entsprechen Erosionsstufen des Rheins. Zur Lage des schematischen Querprofils durch die Niederterrassenfelder s. Abb. 1a. 


\section{B. Geoarchäologische Untersuchungen zur Fund- stelle Basel-Gasfabrik}

\section{Topographische und bodenkundliche Verhält- nisse nördlich von Gaskessel 7 (Fabrikstrasse)}

Aufgrund stratigraphischer Beobachtungen an Bodenprofilen sowie älterer topographischer Aufnahmen ${ }^{16}$ wird ersichtlich, dass im heute weitgehend einplanierten und stark überbauten Gelände der ehemaligen Gasfabrik noch bis zu Beginn dieses Jahrhunderts leicht hervortretende Kuppen und sanfte Senken vorhanden waren. Dieses Relief lässt sich mit den geologischen Verhältnissen erklären: Rheinparallele, längliche Kiesrücken mit geringer Lehmbedeckung bilden dabei die Hochzonen, während die daran anschliessenden Mulden in den Niederterrassenschottern von Hochflutsanden aufgefüllt sind ${ }^{17}$. Bei archäologischen Ausgrabungen wurde diese für die geomorphologischen Verhältnisse typische Situation immer wieder angetroffen. Sie wird im folgenden unter Berücksichtigung geologisch-bodenkundlicher Resultate am Beispiel eines $70 \mathrm{~m}$ langen Südwest-Nordost-Profils westlich der Fabrikstrasse diskutiert. Wir verweisen hier auf den archäologischen Vorbericht (JuD/ SPICHTIG 1992) und beschränken uns auf eine topographische Übersichtsdarstellung.

Das vier archäologische Ausgrabungen ${ }^{18}$ umfassende Untersuchungsgebiet erstreckt sich nördlich des ehemaligen Gaskessels 7, der knapp 300 m vom heutigen Rheinlauf entfernt ist (Abb. 10). Die teils modern aufgeschütteten Geländeoberkanten können in dieser Zone bis auf über $256 \mathrm{~m}$ ü. M. reichen und liegen somit gut $10 \mathrm{~m}$ über dem mittleren Rheinpegel. Wie bereits angedeutet, bestimmt der Verlauf der Rheinschotter die Geländeformen ganz erheblich. Der Kies bildet im Bereich der Grabungen 1994/1 und 1993/13 eine bis auf 255,50 m ü. M. ansteigende Hochzone und fällt nach Südwesten relativ steil, nach Nordosten dagegen gleichmässig in eine Senke ab (Abb. 11). Aus pedologischer Sicht ist der Kiesrücken von untergeordneter Bedeutung, da auf inm bereits zur Latènezeit eine markante Kappung des natürlichen Bodenprofils stattgefunden hat. Dies belegen die unmittelbar über den unverwitterten Rheinschottern liegenden archäologischen Schichten. Leider sind sie in Kuppenlage infolge Erosion - ausgelöst durch Ackerbau und moderne Eingriffe - im allgemeinen schlecht konserviert (Jud/SPICHTIG 1992, 20). Die Feldbefunde der letzten Jahre haben gezeigt, dass sich im Bereich solcher Hochzonen meist nur eingetiefte archäologische Strukturen erhalten haben, während die dazugehörenden Gehniveaus und Planieschichten weitgehend jüngeren Umlagerungs- und Abtragungsprozessen zum Opfer gefallen sind.

In den Mulden sind indessen Reste von alten Bodenbildungen und relativ gut erhaltene archäologische Schichten vorhanden. Diese werden mittels insgesamt 14 mikromorphologischen Bodenproben doku- mentiert, wovon eine Auswahl von vier repräsentativen Stratigraphien abgebildet ist (Abb. 11).

Die geowissenschaftlichen Untersuchungen lieferten namentlich folgende Resultate:

In Profil P308 sind die ins Atlantikum zu datierenden grauen Hochflutsande über $80 \mathrm{~cm}$ mächtig und weisen im oberen Bereich eine Bodenbildung auf. Es handelt sich um den gelbbraunen, leicht lehmigen Verwitterungshorizont (Bv-Horizont) der Hochflutsande. Vergleicht man diese Stratigraphie mit bodenkundlich untersuchten Profilen südlich von Gaskessel 7 (nicht abgebildet), so fällt auf, dass in Profil P308 ein Teil des Oberbodens, bestehend aus Humushorizont und darunterliegendem Mineralboden, fehlt. Noch ausgeprägter ist die Situation im Zentrum der Senke, in den Profilen P211, P058 und P120. Hier liegen die archäologischen Straten mit einer Schichtlücke direkt auf einem schwach verwitterten Hochflutsand (Cv-Horizont) auf. Dieser Bodenhorizont steht in vollständiger erhaltenen Bodenprofilen ${ }^{19}$ erst in einer Tiefe von ungefähr $50 \mathrm{~cm}$ unter der Oberfläche an. Unter der Voraussetzung, dass auf dem Gelände der Gasfabrik die Bodenentwicklung in den Hochflutsanden einheitlich verlief, d. h., dass sich überall vorlatènezeitlich eine Parabraunerde mit der Horizontabfolge Ah-Al-Bvt-Bv(oder $\mathrm{Cv}$ )-C-IIC ausgebildet hat, bedeutet dies, dass

- auch in Muldenlage die Bodenprofile durch die latènezeitlichen Eingriffe künstlich gekappt sind,

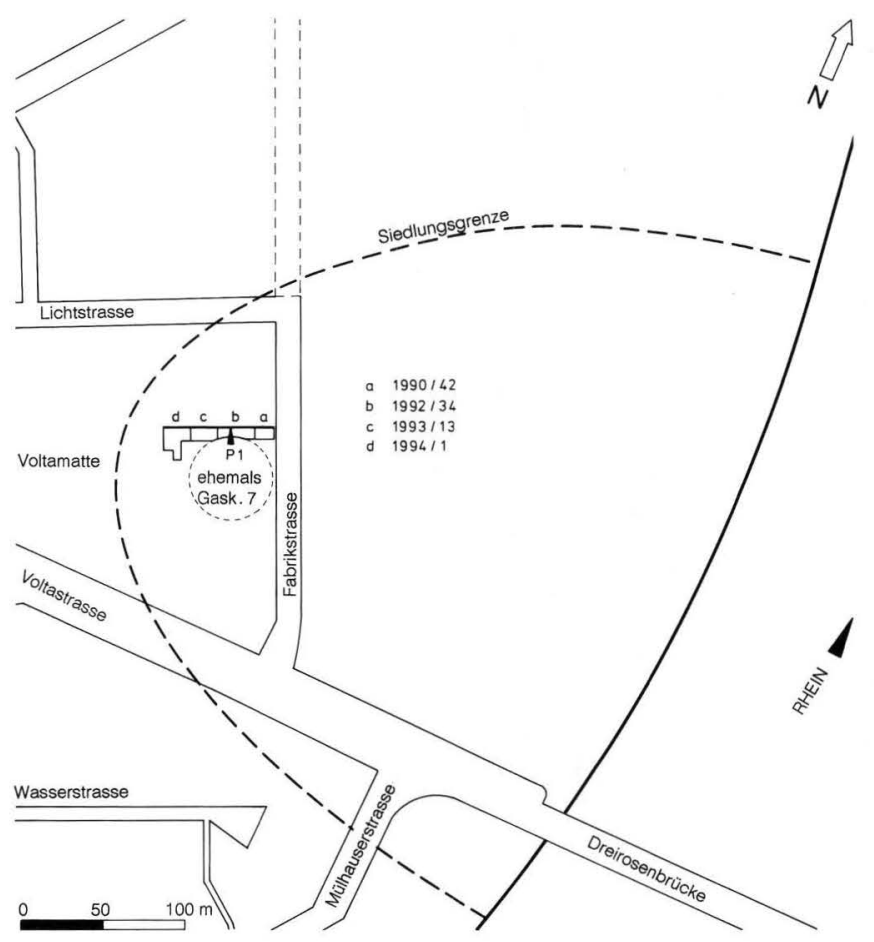

Abb. 10. Lageplan der spätlatènezeitlichen Fundstelle Basel-Gasfabrik. Eingetragen sind die vier Grabungen (a-d) nördlich von Gaskessel 7, an deren nördlichem Grabungsrand das grosse Querprofil durch die Senke zwischen Voltamatte und Fabrikstrasse verläuft (s. dazu auch Abb. 11). 


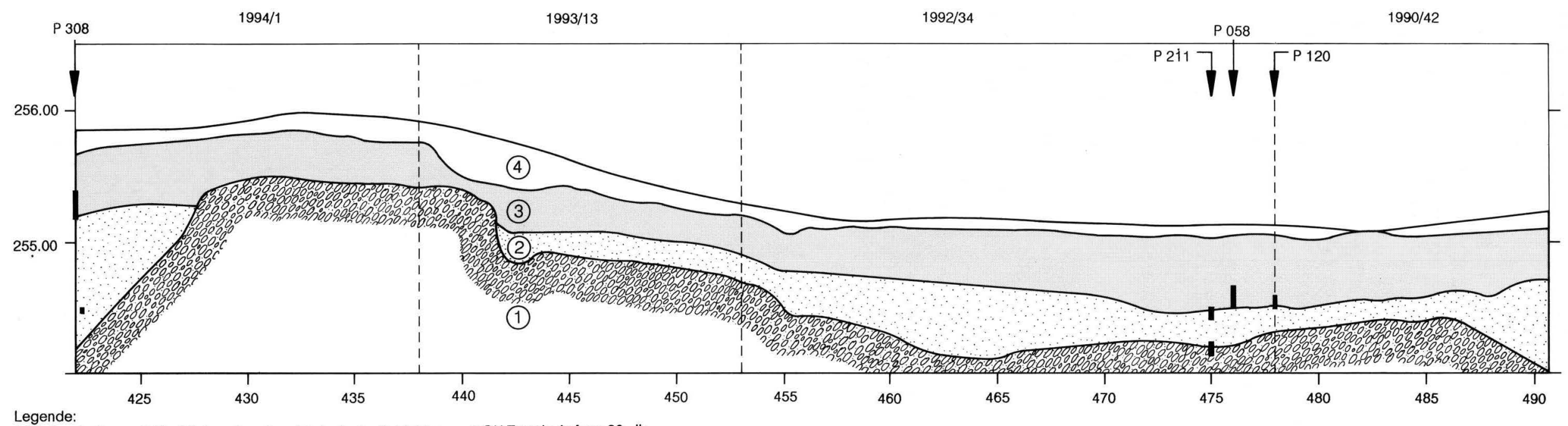

1 Rheinschotter 2 Hochflutsand 3 archäologische Schichten 4 OK Terrain Anfang 20. Jh.
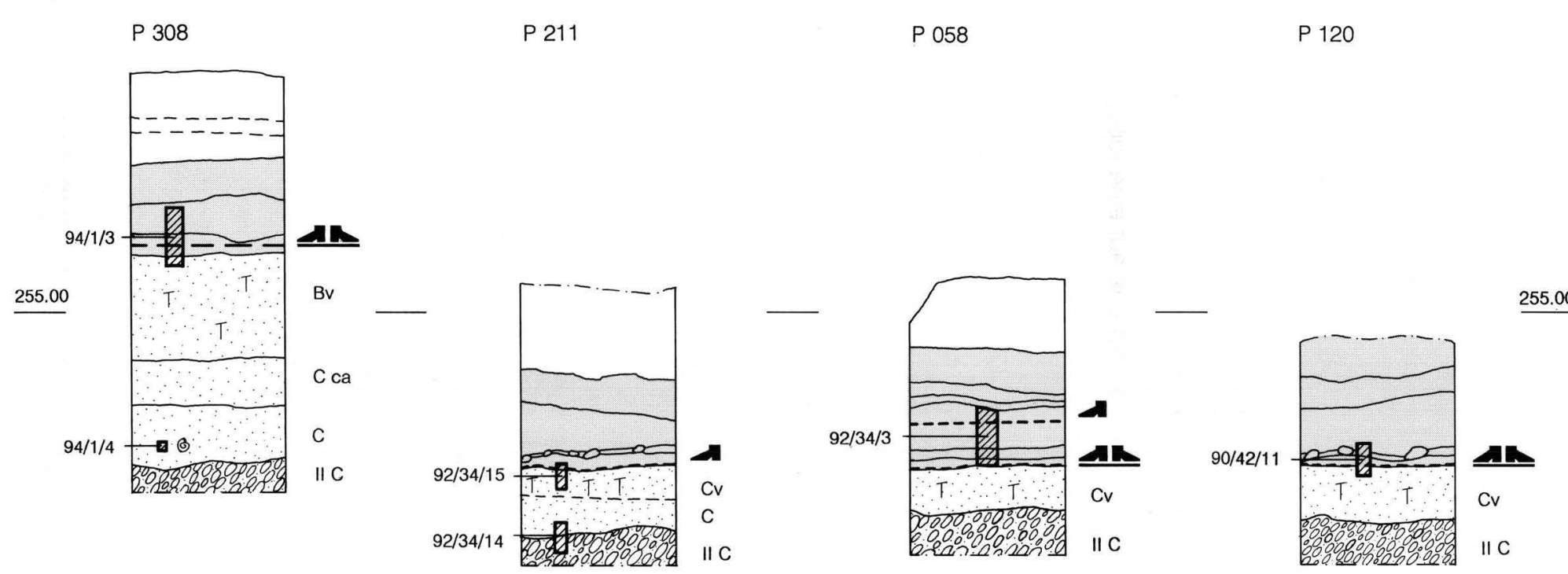

Legende:

Pogog Rheinschotter

Hochflutsand (HFS)

TTT Verwitterter HFS

IL Stampflehmboden

A Kompaktionsspuren

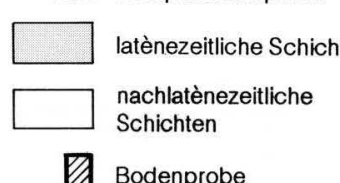

Bodenprobe

Abb. 11. Überhöhtes Profil durch die Geländesenke westlich der Fabrikstrasse auf der Linie 1714 mit der Lage der vier im Text erwähnten Profile P308, P211, P058 und P120. 
- stellenweise bis über $50 \mathrm{~cm}$ des natürlichen Profilaufbaus fehlen,

- alleine für die 4 untersuchten Grabungsflächen nördlich von Gaskessel 7 ein geschätzter Materialabtrag von gegen $120 \mathrm{~m}^{3}$ zur Latènezeit stattgefunden hat.

\section{Phänomenologie}

Die bodenkundlichen und archäologischen Befunde der Zone nördlich von Gaskessel 7 ermöglichen unter Berücksichtigung der bereits unter A.6. Kaiseraugst "Kastell, Jakobli-Haus" und A.7. Basel-Gasfabrik "Fabrikstrasse 5" beschriebenen Stratigraphie des Niederterrassenfeldes B3 (nach WITTMANN 1961) eine annähernde Rekonstruktion der Sedimentations-, Verwitterungs- und Erosionsphasen, die zum heute beobachtbaren Profilaufbau geführt haben (Abb. 12). Die geologisch fassbare Ereignisabfolge wird anhand von 7 schematischen Blockdiagrammen für den Zeitraum vom Atlantikum (ca. 6'000 BC) bis in die Neuzeit dargestellt, wobei der unterschiedlichen Substratverteilung in den Hochzonen und den Senken Rechnung getragen wird. Es sei an dieser Stelle vermerkt, dass die chronologischen Anhaltspunkte in den Aufschlüssen an der Fabrikstrasse 5 nicht unbesehen auf alle Schichtenfolgen im Areal der Gasfabrik zu übertragen sind. Obschon das Gebiet um den Gaskessel 7 gewissermassen Modellcharakter für die Ablagerungsräume auf dem B3-Niederterrassenfeld besitzen mag, muss die Sedimentation der Hochflutsande nicht überall zur gleichen Zeit erfolgt sein. Punktuelle malakologische Analysen der einheitlich scheinenden Hochflutsande werden deshalb auch in Zukunft für chronostratigraphische Fragestellungen von grundlegender Bedeutung sein.

Die geologische Rückblende (Abb. 12) beginnt zum Zeitpunkt einer starken fluviatilen Überformung eines Schotterfeldes, was letztlich zur Bildung der Kiesrücken und der Mulden geführt hat. Nach dieser Aktivitätsphase des Rheins ist mit einem kurzen Ablagerungsunterbruch (< 100 Jahre ?) zu rechnen, währenddem eine schwache Frostverwitterung der Kiesoberfläche stattfindet. Eine erneute Flussaktivität setzt im Atlantikum ein: Die Kiesterrasse wird vom breiten, mäandrierenden Rhein periodisch überflutet. Jedes dieser Hochflutereignisse sedimentiert dabei etwas grauen, kalkreichen Feinsand auf, der zum Schluss in Muldenlage bis über $2 \mathrm{~m}$ mächtig sein kann. Die Sedimentationsdauer dieser typischen flood-plain Ablagerungen (REINECKE/SINGH 1980) ist schwer abschätzbar und dürfte sicher mehrere Jahrhunderte, im Maximum gar einige Jahrtausende Flussgeschichte dokumentieren. Erst mit dem Absinken des Rheinpegels ist die Hochflutsedimentation abgeschlossen, und es beginnt eine Bodenbildung unter geschlossener Vegetationsdecke. Sie führt bis zur jüngeren Eisenzeit zu einer markanten Profildifferenzierung in Form einer Parabraunerde mit Humushorizont (Ah), Tonauswaschungshorizont (Al), schwachem Tonanreicherungs- horizont (Bvt) und leicht verwittertem Feinsand (Cv) über dem Ausgangsgestein (C). Dieses im Laufe von vielen Jahrhunderten entstandene Gleichgewicht wird mit der latènezeitlichen Nutzung des Gebietes empfindlich gestört. Zu dieser Zeit erfolgt - sowohl auf den Kuppen als auch in den Senken - ein künstlicher Abtrag des Oberbodens, was durch die Gehniveaus auf dem gekappten Cv-Horizont belegt ist. Die nachfolgende spätlatènezeitliche Sedimentationsgeschichte (s. B.2. Spätlatènezeitliche Ablagerungen) ist stark geprägt von anthropogenen Einflüssen, wie

- Aushub (und Einfüllen) von Gruben,

- Bau und Abbruch von Wohnstrukturen,

- Umlagerung und Ausbreitung von Erdmaterial,

- Eintrag menschlicher Fäkalien sowie

- Deponierung von Stoffen, die im Allgemeinen in der Archäologie als Abfall bezeichnet werden.

Dieses spätlatènezeitliche Sedimentationsgeschehen führte vorab zur Bildung von Planieschichten. Durch natürliche Einebnungs- und Durchmischungsvorgänge sowie durch jüngere landwirtschaftliche Tätigkeiten wurden die archäologischen Schichten in exponierter Kuppenlage erodiert und zerstört, wogegen die tiefergelegenen archäologischen Niveaus in den Senken nur wenig beeinträchtigt worden sind.

\section{Spätlatènezeitliche Ablagerungen}

\subsection{Ein Lehmboden}

Im vorangehenden Kapitel ist bereits erwähnt worden, dass sich die archäologischen Strukturen in den Geländesenken relativ gut erhalten haben. Nachfolgend wird deshalb exemplarisch auf stratigraphische Befunde aus vier Grabungen nördlich von Gaskessel 7 eingegangen, wobei das wohl wichtigste Resultat der Nachweis eines in mehreren mikromorphologischen Bodenproben vorhandenen Stampflehmbodens ist. Dieser lässt sich allerdings makroskopisch nur schwer fassen und konnte deswegen während der Feldarbeiten auch nicht erkannt werden ${ }^{20}$. Er befindet sich in stratigraphisch tiefer Lage, am Übergang vom natürlich anstehenden Lehm zu den basalen latènezeitlichen Schichten. Zur Illustration der mikroskopischen Befunde sei auf die Bodenprobe 92/34/3 aus Profil P058 (s. auch Abb. 11) verwiesen. Diese knapp 22 $\mathrm{cm}$ hohe Probe lässt sich in ingesamt 5 Schichten gliedern (Abb. 13a):

An der Basis erkennt man den künstlich gekappten Verwitterungshorizont der Hochflutsande (Schicht 8), der hier durch Bioturbation mit holzkohlehaltigem Lehm aus den darüberliegenden Schichten 5-7a vermischt ist. Wie am Beispiel von Schicht 8 deutlich wird, stelIen die Bioturbationsphänomene, d.h. die Durchmischungsvorgänge durch Bodenlebewesen, ein in der Gasfabrik häufig beobachtetes Merkmal dar, das negative Auswirkungen auf die Erhaltung archäologischer Strukturen haben kann. Die deutliche Bioturbation in Schicht 8 resultiert aber nicht allein aus moderner 
1.
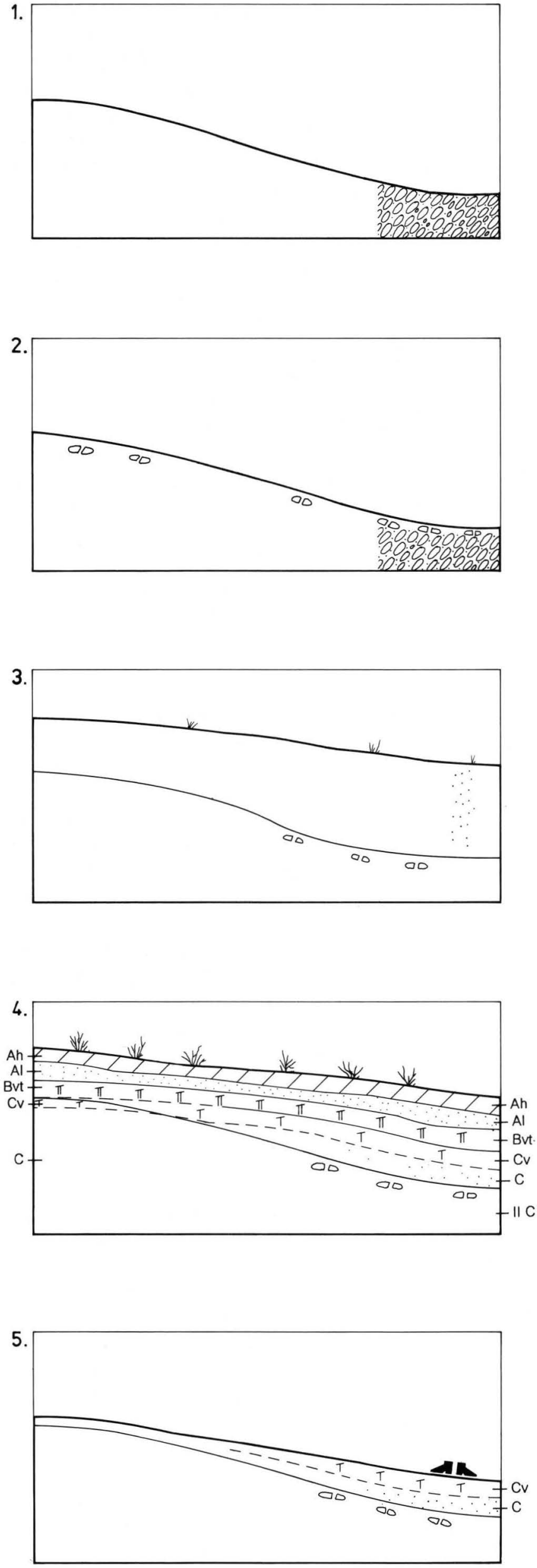

6.

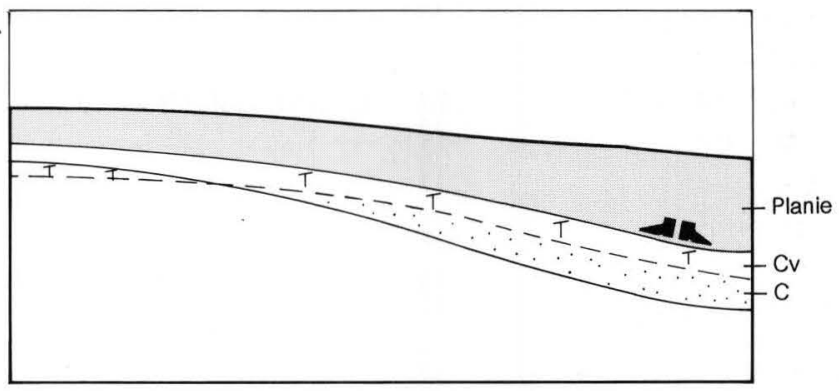

7.

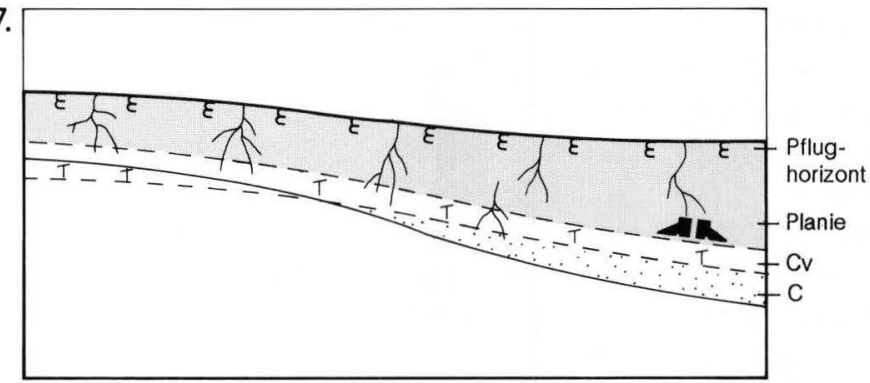

Abb. 12. Stark vereinfachte Rekonstruktion der Sedimentations- und Verwitterungsprozesse, die in der Fundstelle Basel-Gasfabrik (Bereich "Fabrikstrasse $5^{\prime \prime)}$ in den letzten 8'000 Jahren abgelaufen sind. Die geologisch fassbaren Ereignisse wurden in schematisierter Form für Senken als auch für Hochzonen dargestellt.

1 Erosion (?): Herausbildung des Niederterrassenfeldes B3 im Atlantikum oder (wenig) früher

2 leichte Verwitterung der Kiesoberfläche

3 fluviatile Sedimentation: periodische Ablagerung von Hochflutsanden durch den mäandrierenden Rhein, seit dem Atlantikum

4 Ende der fluviatilen Aktivität und Verwitterung der Hochflutsande: Bodenbildung unter einer Vegetationsdecke. Noch vor dem 1. Jh. v. Chr. wird das Stadium einer schwach ausgeprägten Parabraunerde erreicht. In den Hochzonen werden auch die Rheinschotter von der Verwitterung erfasst

5 menschliche Eingriffe während der latènezeitlichen Besiedlung: Abtrag des Oberbodens, Anlage von Stampflehmböden innerhalb von Baustrukturen, Ausheben von Gruben

6 anthropogene Sedimentation: Bildung von latènezeitlichen Planieschichten und Steinakkumulationen; anthropogener Sedimentauftrag (und möglicherweise auch Abtrag)

7 Verwitterung der latènezeitlichen Planien durch Bodenbildungsprozesse und jüngere, landwirtschaftliche Tätigkeiten (Mittelalter/Neuzeit) 


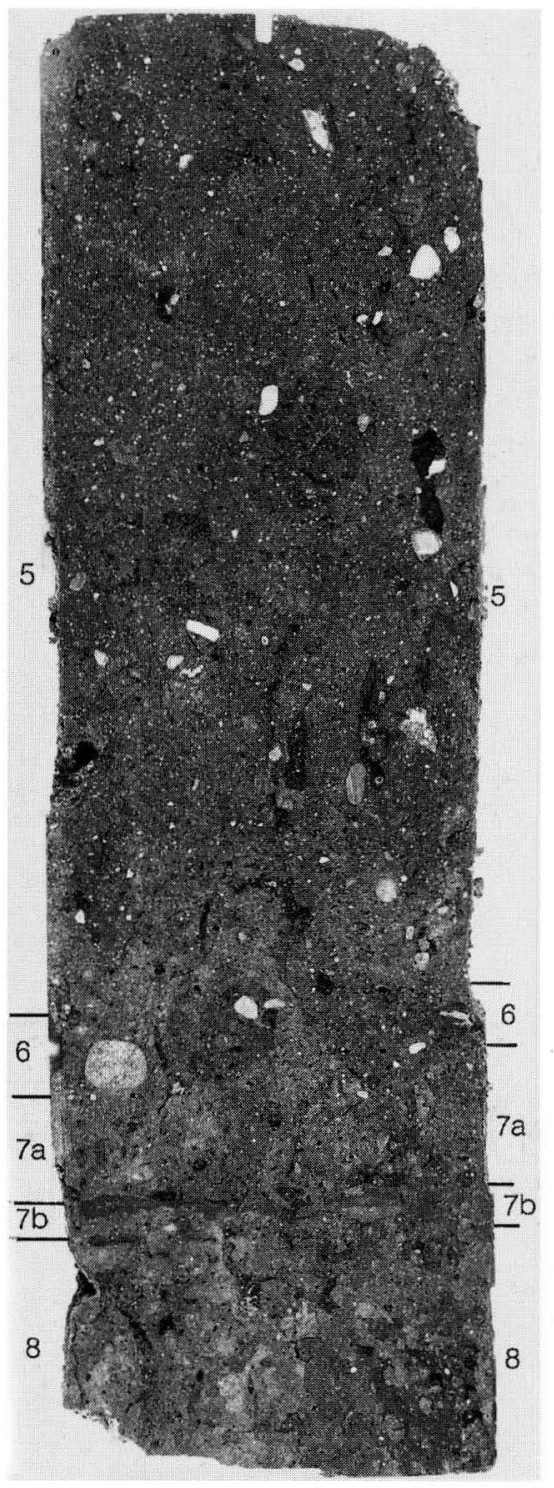

Abb. 13a. Basel-Gasfabrik, „Fabrikstrasse 5“. Mit Kunstharz gefestigte Sedimentprobe 1992/34/3 mit den Schichten 5-8. Zum Beschrieb und zur Interpretation der einzelnen Schichten s. Abb. 13e. - Höhe des Präparates: $22 \mathrm{~cm}$.

Abb. 13b. Mikrophoto der Bodenprobe 92/34/3, Schicht 7. In der Bildmitte erkennt man das basale spätlatènezeitliche Gehniveau, hier in Form eines gestampften Lehmbodens mit typischer, massiver Mikrostruktur (Schicht 7b). Darüber liegt die locker gelagerte Planieschicht 7a, deren kalkhaltiger Feinsand aus der Verwitterung von Hüttenwänden stammt. - Bildbreite: 4,4 mm, PPL.

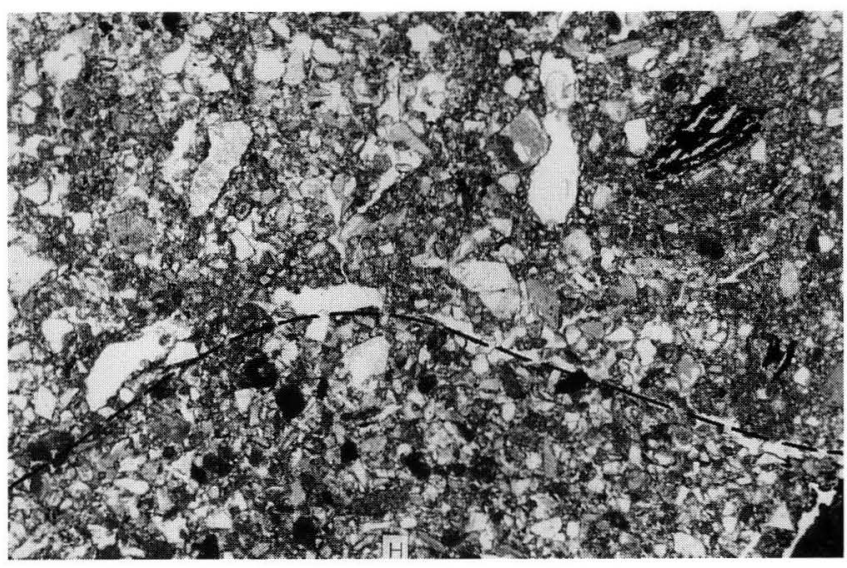

Abb. 13c. Mikrophoto der Bodenprobe 92/34/3, Schicht 5. Sandige Planieschicht mit brauner, organischer Matrix und Holzkohleflittern („,dark earth“). In der unteren Bildhälfte ist ein verwittertes, jedoch unverbranntes Hüttenlehmfragment $(H)$ aus kalkhaltigem Feinsand zu sehen. Derartige fragmentierte Lehmwandbestandteile stellen neben den Kiesakkumulationen die weitaus häufigste anorganische Komponente in den spätlatènezeitlichen Planieschichten dar. - Bildbreite: 4,4 mm, PPL.

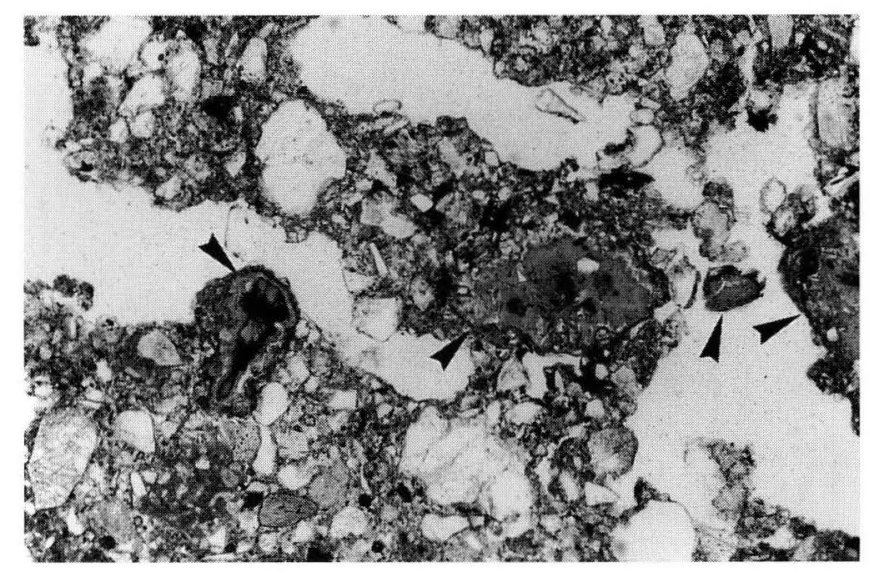

Abb. 13d. Mikrophoto der Bodenprobe 92/34/3, Schicht 5. Sandige Planieschicht aus aufgelöstem Hüttenlehm und Holzkohle, durchsetzt mit vielen, stark fragmentierten menschlichen Koprolithen (Pfeile). - Bildbreite: $4,4 \mathrm{~mm}$, PPL.

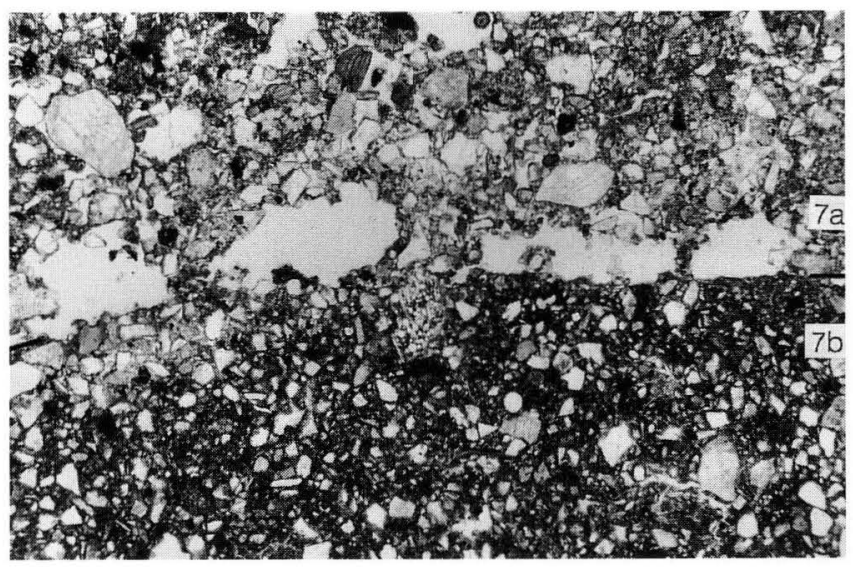


Durchwurzelung: Sie ist vielmehr ein Hinweis darauf, dass während und nach der Bildung der spätlatènezeitlichen Planieschichten 5-7a in diesen eine intensive biotische Aktivität herrschte, die durch den hohen Reichtum an Nährstoffen (organisches Material, Asche, Koprolithen) begünstigt wurde.

Über der Schicht 8 folgt ein bis $6 \mathrm{~mm}$ mächtiges, lehmiges Band (Schicht 7b), das ein massives, d.h. nahezu porenfreies Gefüge ${ }^{21}$ und eine scharf begrenzte Oberfläche aufweist (Abb. 13a, 13b). Wir fassen hier unzweifelhaft die Reste eines gestampften Lehmbodens, der aus einem stark verdichteten Gemisch von Lehm, kalkhaltigem Feinsand und feinsten Holzkohleflittern besteht ${ }^{22}$. Machart und Erhaltungsgrad sprechen eher gegen einen der Witterung ausgesetzten Bodenbelag ${ }^{23}$, daher ist sehr wahrscheinlich, dass der Boden überdacht war. Mit Ausnahme einiger fragmentierter, oberflächlich in den Lehm eingetretener Molluskenschalen liegen unmittelbar über dem Hüttenboden keine Funde: Im antiken Gehniveau liessen sich weder Knochensplitter noch Keramikfragmente oder gar Eisenobjekte beobachten. In vergleichbarer stratigraphischer Lage sind Reste eines Stampflehmbodens unter anderem auch in den Proben 94/1/3 und 90/42/11 nachgewiesen worden, wobei sich letzterer von den übrigen Lehmböden leicht unterscheidet. Hier wurden namentlich eine unregelmässige, relativ schlecht erhaltene Bodenoberfläche und starke Einschwemmungen von Feinmaterial in die darunterliegende Schicht beobachtet, beides Indizien, die in diesem speziellen Fall eher gegen eine Überdachung sprechen.

\subsection{Planieschichten}

Die Lehmböden werden überlagert von einer mehrere Zentimeter mächtigen Schicht locker gelagerten Feinsandes ${ }^{24}$ (Abb. 13b). In Probe 92/34/3 führt Schicht 7 a auffällig viele Kalkpartikel der Silt- und Feinsand- fraktion, ist jedoch abgesehen von etwas Holzkohle steril, womit eine Deutung als Benutzungsschicht ${ }^{25}$ entfällt. Wie weiter unten am Beispiel von Schicht 5 gezeigt wird, stammt ein Grossteil der feinen Kalksandfraktion der Planien nachweislich aus der Verwitterung von Lehmwänden. Letztere bestanden in den beiden keltischen Fundstellen von Basel (Gasfabrik und Münsterhügel) aus einem organisch gemagerten Feinsand ${ }^{26}$; sie wandelten sich bei einem Brand in verbackene und teils mit Rutenabdrücken durchsetzte Lehmfragmente um. Solche brandgeröteten Lehmwandbestandteile lassen sich daher makroskopisch meist problemlos erkennen, hingegen ist der Nachweis von unverbranntem Hüttenlehm in der Regel weit schwieriger, da die durch Feuer verursachten Farbund Strukturveränderungen fehlen. Intensive Verwitterung kann darüberhinaus zu einer vollständigen Auflösung führen, so dass von der ehemaligen Lehmwand lediglich ein lockerer, unorganisierter Kalksand zurückbleibt. Mittels mikromorphologischer Analysen lassen sich in solchen sandigen Kulturschichten gelegentlich kleinste Lehmwandreste nachweisen, die sich aufgrund ihrer charakteristischen Merkmale wie Feinschichtung, Porenverteilung, petrographisches Spektrum und Magerung klar zu erkennen geben (Abb. 13c). Auch Schicht 7 a dürfte sich aufgrund der optischen Untersuchungen zur Hauptsache aus ebensolchen Lehmwandbestandteilen zusammensetzen und damit einen Abbruchhorizont resp. eine Planieschicht darstellen.

Die darüberfolgende Schicht 6 markiert das unterste archäologische Fundniveau. Es zeichnet sich als wenige Zentimeter mächtige, feinkiesige Lage mit hoher Funddichte ab. Unter dem Mikroskop beobachtet man korrodierte Eisenobjekte, kantenverrundete Keramik, Knochen, Schlacken, brandgeröteten Kies, Herdlehmfragmente sowie unverbrannten Hüttenlehm (Abb. 13a) ${ }^{27}$. Die Matrix besteht wie in Schicht 7 a aus einem kalkhaltigen Feinsand, der stark mit Holzkohle und weni-

\begin{tabular}{|c|c|c|c|c|c|c|c|}
\hline Schicht & Sediment & $\begin{array}{l}\text { Kompaktions- } \\
\text { anzeiger }\end{array}$ & Holzkohle & $\begin{array}{l}\text { Menschliche } \\
\text { Koprolithen }\end{array}$ & Bioturbation & Funddichte & Interpretation \\
\hline $\begin{array}{c}\text { oben } \\
5 \text { Mitte } \\
\text { unten }\end{array}$ & $\begin{array}{l}\text { Dunkelbrauner } \\
\text { sandiger Lehm }\end{array}$ & $\begin{array}{l}- \\
+- \\
-\end{array}$ & $\begin{array}{l}++ \\
++ \\
++\end{array}$ & $\begin{array}{l}+ \\
+ \\
+\end{array}$ & $\begin{array}{l}++ \\
++ \\
++\end{array}$ & $\begin{array}{c}+- \\
- \\
-\end{array}$ & Planie \\
\hline 6 & $\begin{array}{l}\text { Feinkiesiger } \\
\text { Lehm }\end{array}$ & - & + & +- & + & ++ & $\begin{array}{l}\text { Planie, } \\
\text { Fundniveau }\end{array}$ \\
\hline $7 a$ & $\begin{array}{l}\text { Brauner } \\
\text { lehmiger Sand }\end{array}$ & - & + & +- & + & - & Planie \\
\hline $7 b$ & Gelber Lehm & ++ & - & - & + & - & Lehmboden \\
\hline 8 & $\begin{array}{l}\text { Graubrauner } \\
\text { Feinsand }\end{array}$ & - & - & - & +- & - & $\begin{array}{l}\text { Anstehender } \\
\text { Sand }\end{array}$ \\
\hline
\end{tabular}

++ : sehr viel

+ : viel

+-: wenig

-: abwesend

Abb. 13e. Basel-Gasfabrik, "Fabrikstrasse 5“. Resultate der geoarchäologischen Untersuchungen an Sedimentprobe 1992/34/3, Schichten 5-8. 
gen menschlichen Koprolithen durchsetzt ist. Kompaktionsanzeiger - als Hinweis auf ein intensives Begehen der Oberfläche - sind nicht erkennbar. Bei Schicht 6 kann es sich somit kaum um einen längerfristig offengelegenen Gehhorizont handeln, auf welchem eine relative Fundanreicherung in der Art eines Reduktionsniveaus stattgefunden hat. Viel eher dürfte es sich um fundreiches, ausplaniertes Erdmaterial, also ebenfalls um eine Planieschicht handeln. Da folglich ein aufgetragenes und ausgebreitetes Sediment unbekannter Herkunft vorliegt, müssen die darin enthaltenen archäologischen Objekte nicht zwingend in stratigraphischer Beziehung zum darunterliegenden Stampflehmboden stehen.

Die oberen $14 \mathrm{~cm}$ in Probe 92/34/3 werden von Schicht 5 , einem homogenen, dunkelbraunen sandigen Lehm eingenommen. Unter dem Mikroskop zeigt sich ein bioturbiertes Gemisch aus verwitterten Lehmwänden, Holzkohleflittern, Asche und organischem Material. Ferner finden sich einige Hundekoprolithen sowie überraschend viele menschliche Fäkalien ${ }^{28}$ (Abb. 13d). Aufgrund der organischen Porenfüllungen und der Staunässeanzeiger (Vivianitbildungen in Fäkalien und Eisenausfällungen) darf ein feuchtes, schlammiges Ablagerungsmilieu mit schlechten Drainageeigenschaften rekonstruiert werden. Im mittleren Teil von Schicht 5 lassen undeutlich ausgebildete siltige Einschaltungen ${ }^{29}$ auf einen möglichen Sedimentationsunterbruch mit nachfolgender Begehung (trampling) schliessen. Evidente archäologische Strukturen in der Art des Lehmbodens wie z. B. Schicht 7b sind hingegen nicht vorhanden. Bezüglich der Genese von Schicht 5 können wir festhalten, dass es sich um eine rasch gebildete Planieschicht mit einer Matrix aus Bauschutt und Herdstellenabraum handelt, die nach ihrer Ablagerung einer intensiven Verwitterung unterworfen war. Die vielen menschlichen Koprolithen und die starke Durchwühlung durch Bodenlebewesen zeigen eine aufgelassene Zone ohne unmittelbare Siedlungsaktivität an. Vom Sedimenttyp her steht Schicht $5 \mathrm{da}-$ durch den sog. "dark earth" Ablagerungen nahe, ein Begriff, der homogene, makroskopisch nicht weiter differenzierbare dunkle Sedimente verschiedensten anthropogenen Ursprungs beinhaltet (COURTY et al. 1989, 261).

\subsection{Deutung}

Die mikromorphologisch untersuchten Bereiche - die jeweils unteren $30 \mathrm{~cm}$ eines insgesamt bis $50 \mathrm{~cm}$ mächtigen spätlatènezeitlichen Schichtkomplexes - zeigen starke Gemeinsamkeiten in Bezug auf die Sedimenttypen und deren Genese. So besteht die Schichtabfolge vorab aus Planien (in Probe 92/34/3 beispielsweise die Schichten 5, 6 und 7a), die das unterste spätlatènezeitliche Fundniveau einschliessen. Die Planieschichten überlagern jeweils gut erhaltene Stampflehmböden, die sich direkt über dem künstlich gekappten Alluvialsand befinden. Aufgrund ihrer Ausprägung dürfen diese - mit Ausnahme von Probe 90/
42/11 - mit Baustrukturen (von der Überdachung der Böden) in Verbindung gebracht werden.

Bei den Planien über diesem antiken Gehniveau handelt es sich um von Menschen aufgetragene Sedimente, die aus der Ablagerung und Verwitterung von Bauschutt, vermischt mit Artefakten aller Art, hervorgegangen sind. Nachweisbar ist ferner ein markanter Eintrag menschlicher Fäkalien, möglicherweise erst zu einem Zeitpunkt, als Teile des Geländes bereits aufgelassen waren und brachlagen ${ }^{30}$. Dafür spricht indirekt auch die starke Bioturbation, die zu einer fortgeschrittenen Homogenisierung der Sedimente innerhalb der Planieschichten geführt hat. In diesem Zusammenhang sei auf die mikromorphologischen Untersuchungen von MACPHAIL (1994) an „dark earth“ Ablagerungen in Grossbritannien verwiesen. Es zeigte sich, dass in aufgelassenen römischen Stadtgebieten Londons die natürlichen pedogenen Prozesse wie Bioturbation und chemische Verwitterung die unterschiedlich zusammengesetzten urbanen Sedimente aus Lehmfachwerkbauten und Siedlungsabfällen in weniger als zwei Jahrhunderten in homogene "dark earth" Ablagerungen umgewandelt haben. Derselbe Autor verglich diese archäologischen Sedimente mit jungen Böden aus Zerstörungsschutt des Zweiten Weltkrieges, von denen aufgrund bodenkundlicher Untersuchungen bekannt war, dass sich in rund 30 Jahren lithomorphe Böden (Pararendzinen) mit bis zu $15 \mathrm{~cm}$ mächtigen Humushorizonten aus Ziegelbruch und Mörtel bilden.

Dass in unserem Untersuchungsgebiet westlich der Fabrikstrasse während der Latènezeit mit einer zeitweilig nicht überbauten Zone im Bereich der Fundstelle zu rechnen ist ${ }^{31}$, wird auch durch die hydromorphen Sedimentmerkmale angezeigt. Vorab in den Senken ist daher mit feuchten Bodenverhältnissen und periodisch stehendem Oberflächenwasser zu rechnen. Ob die über den Lehmplanien folgenden spätlatènezeitlichen Steinakkumulationen ${ }^{32}$ - hier nur am Rande erwähnt, da mikromorphologisch nicht analysiert - in Beziehung zu den Staunässeanzeigern stehen und allenfalls Bemühungen um oberflächliche Drainage der Geländemulden darstellen, lässt sich vorläufig noch nicht entscheiden.

\section{Schlussfolgerungen}

Betrachtet man die Schichtenfolge der spätlatènezeitlichen Ablagerungen nördlich des Gaskessels 7, so fällt auf, dass teilweise eine erhebliche Diskrepanz zwischen den Feldbeobachtungen und den Ergebnissen der mikroskopischen Untersuchungen herrscht. Dies betrifft besonders die Lokalisierung des antiken Gehniveaus, das sich in unseren Proben nicht im oder auf dem feinkiesigen, untersten Fundniveau („Kieselischicht“"33), sondern unterhalb desselben befindet. In diesem archäologisch sterilen Abschnitt der Stratigraphie haben sich Reste von gestampften Lehmböden erhalten, die in situ Befunde darstellen. Lässt sich die 
Zusammensetzung und die Entstehung der die Lehmböden überdeckenden Planien relativ klar umschreiben, so ist der Herkunftsort des ausplanierten Materials nicht eruierbar. Ob die darin enthaltenen Fundensembles geschlossen sind und in welcher Relation sie zum Gehniveau stehen, ist daher eine noch offene Frage. Bei der archäologischen Auswertung der entsprechenden Funde sollte auf diese Problematik in Zukunft ein spezielles Augenmerk gerichtet sein. Aus geoarchäologischer Sicht ist die Rekonstruktion der Schichtgenese im Detail noch mit einer Menge ungelöster Fragen behaftet, dennoch zeichnen sich zwei Mechanismen recht deutlich ab: einerseits der massive Abtrag, andererseits der ebenso starke Auftrag von Sediment. Die Abtragungsvorgänge sind durch die pedologischen Beobachtungen belegt, wobei namentlich die stratigraphische Lage des Lehmbodens eine grossflächige Kappung des natürlichen Bodenprofils impliziert. Ein beträchtlicher Sedimentauftrag folgt - nach einer ersten fassbaren Siedlungsphase im Zusammenhang mit Planierungen von Bauschutt (Lehmwänden) und Siedlungsabfällen. Wir fassen damit ein sukkzessives Anwachsen ${ }^{34}$ einer Schichtenfolge, die durch einen Wechsel von periodisch hoher Sedimentationsrate und Verwitterungsphasen geprägt ist und letztlich aus makroskopisch schwer differenzierbaren Ablagerungen urbanen Charakters besteht.

\section{Bibliographie}

D' Aujourd'Hul et al. 1976

R. d' Aujourd'hui et al., "Basel-Gasfabrik, Voltastrasse 30 und Rheinafen St. Johann" (Jber. 1975), BZ 76 , 1976, 200-236.

Courty et al. 1989

M. A. Courty, P. Goldberg, R. Macphail, Soils and micromorphology in archaeology, Cambridge 1989.

FISCHER et al. 1971

H. Fischer, L. Hauber, O. Wittman, Geologischer Atlas der Schweiz 1:25000, Blatt 1047, Basel: Erläuterungen, Bern 1971.

GRAUL 1962

H. Graul, "Die Niederterrassenfelder im Umkreis von Basel", in: Eiszeitalter und Gegenwart, Bd. 13, 181196; Öhringen/Württemberg 1962.

\section{GuÉLAT 1993}

M. Guélat, "La dynamique fluviatile et palustre dans les vallées jurassiennes au cours des derniers 15'000 ans: l'exemple de la région des Montoyes (Jura, Suisse)": M. Guélat, A.-M. Rachoud-Schneider, I. Eschenlohr et P. Paupe, "Archives palustres et vestiges de l'Age du Bronze entre Glovelier et Boécourt (JU, Suisse)", Cahiers d'archéologie jurassienne 4, 1993, 15-52.
Jud/SPICHTIG 1992

P. Jud, N. Spichtig, "Vorbericht über die Grabungen 1992 in der spätkeltischen Siedlung Basel-Gasfabrik", JbAB 1992, 19-35.

\section{LASSAU 1995}

G. Lassau, "Die Grabung 1994.13 im Gräberfeld „Im Sager", Ein Vorbericht", JbAK 16, 1996, 79-90.

\section{LIPPS/CASPERS 1990}

S. Lipps und G. Caspers, "Spätglazial und Holozän auf der Stolzenauer Terrasse im Mittelwesertal", in: Eiszeitalter und Gegenwart, Bd. 40, 111-119, Hannover 1990.

\section{MACPHAIL 1994}

R. Macphail, "The reworking of urban stratigraphy by human and natural processes", in: A.R. Hall and H.K. Kenward (eds.), Urban-rural connexions: perspectives from environmental archaeology, 13-43, Oxbow Monograph, Vol. 47, Oxford 1994.

\section{MOOR, Rentzel, Richner 1994}

B. Moor, Ph. Rentzel, K. Richner, "Der Murus Gallicus auf dem Basler Münsterhügel, Grabung 1990": Ph. Rentzel, "Vorbericht zu den geologisch-bodenkundlichen Untersuchungen", in: P. Jud (ed.), Die spätkeltische Zeit am südlichen Oberrhein, Kolloquium Basel, 17./18. Oktober 1991, 22-28, Basel 1994.

\section{MÜLLER 1995}

U. Müller, "Ausgrabungen in Kaiseraugst im Jahre 1994", JbAK 16, 1995, 65-78.

\section{MÜlLeR et al. 1984}

W.H. Müller, M. Huber, A. Isler, P. Kleboth, Erläuterungen zur Geologischen Karte der zentralen Nordschweiz (Spezialkarte Nr. 121), Nagra und Schweiz. geol. Komm. (1984).

\section{REINECK/SINGH 1980}

H.-E. Reineck, I.B. Singh, Depositional sedimentary environments, With reference to terrigenous clastics; Berlin 1980.

\section{Rentzel 1994}

Ph. Rentzel, "Geologische Untersuchungen auf dem Gelände der spätlatènezeitlichen Siedlung Basel-Gasfabrik, Eine erste Bilanz", in: P. Jud (ed.), Die spätkeltische Zeit am südlichen Oberrhein, Kolloquium Basel, 17./18. Oktober 1991, 49-55, Basel 1994.

Rentzel (in Vorb.)

Ph. Rentzel, "Mikromorphologische Untersuchungen, Ein Beitrag zur Quartärgeologie, zur Bodenkunde und zur Interpretation der archäologischen Strukturen (Murus Gallicus)", in: K. Richner, Ausgrabungen im Bereich des Murus Gallicus auf dem Basler Münsterhügel (Arbeitstitel), ABS, Heft 12 (in Vorbereitung). 
SCHIRMER 1983

W. Schirmer, "Die Talentwicklung an Main und Regnitz seit dem Hochwürm", Geologisches Jahrbuch, Reihe A, 71, 1983, 11-43.

SCHMID 1950

E. Schmid, "Die geologische Einordnung der Fundstelle des urnenfelderzeitlichen Helmes von Weil am Rhein", Jahresbericht und Mitteilungen des oberrheinischen Geologischen Vereins, NF XXXII, 50, 128134.

Schwarz (in Vorb.)

P.-A. Schwarz, Kastelen 1, Die Holzbauten auf dem Kastelenplateau, Forschungen in Augst, Bd. 21 (in Vorbereitung).

\section{VAN VIET-LANOË 1990}

B. Van Vliet-Lanoë, "The genesis and age of the argillic horizon in weichselian loess of northwestern Europe", Quaternary International 5, 1990, 49-56.

\section{WITTMANN 1961}

O. Wittmann, Die Niederterrassenfelder im Umkreis von Basel und ihre kartographische Darstellung, Basler Beiträge zur Geographie und Ethnologie, Bd. 3, Basel 1961.

\section{Anmerkungen}

1 Für die Übersetzung ins Englische möchte ich P. Valentin und $\mathrm{M}$. Arnold-Cooper herzlich danken.

2 S. dazu auch Rentzel (in Vorb.)

3 Mein Dank geht an: G. Helmig, P. Jud, U. Müller, K. Richner, P. A. Schwarz und N. Spichtig.

4 Nach Wittmann (1961) stellt das A1-Feld der Niederterrasse ein Akkumulationsniveau dar, während alle übrigen tieferen Terrassenfelder Erosionsniveaus entsprechen sollen.

5 Zum Nachweis einer spätglazialen sowie einer frühholozänen Illuvialphase in nordwesteuropäischen Lössablagerungen s. auch VAN VLIet-Lanoë $(1990,54)$.

6 Die Schwemmlössdecken mit der Parabraunerde der Kaiseraugster Fluren "Im Sager" und „Im Liner" wurden in römischer Zeit zur Ziegelherstellung ausgebeutet, wobei man die verschiedenen Bodenhorizonte (Ah, Al, Bt und $\mathrm{C}$ ) an Ort und Stelle in rechteckig abgestochenen Gruben miteinander gemischt hat.

7 Für die tonmineralogischen Analysen sei an dieser Stelle Prof. M. Maggetti von der Universität Fribourg bestens gedankt.

8 J.-N. Haas, Pollenanalysen Bäumleingasse 14 (1992/29) - Kurzbericht, $3 p$

9 Eine solche Verwitterungsdecke müsste beispielsweise Kryoturbationen und/oder interstadiale Bodenbildungen zeigen.

10 Bereich nördlich und südlich von Gaskessel 7.

11 S. dazu auch Rentzel 1994, 49.

12 Mündliche Mitteilung N. Thew, Neuchâtel.

13 Vermutete Grösse des spätlatènezeitlichen Siedlungsareals: ca. 12 ha. Freundliche Mitteilung von N. Spichtig.
14 Zur Diskussion über die Entwicklung und das Alter des Bt-Horizontes S. auch ReNtzel (in Vorb.).

15 S. dazu z. B. Schirmer 1983, LipPS/CASPERS 1990

16 Geländeaufnahmen von 1899. StAB: Plan C2 DAB60.

17 S. dazu auch Rentzel. 1994.

18 Laufnummern der Ausgrabungen: 1990/42, 1992/34, 1993/13 $1994 / 1$

19 S. z. B. unter A.6. Kaiseraugst "Kastell, Jakobli-Haus" und A.7 Basel-Gasfabrik "Fabrikstrasse 5". Auch in den Grabungen 1990/37 oder 1996/7 wurden Reste von schwach entwickelten Parabraunerden gefunden.

20 S. dazu auch Jud/SPICHTIG 1992, 21.

21 Porosität: < 1\%.

22 Für die interessanten Diskussionen bezüglich der Bodenprobe 92/34/3 sei R. Macphail herzlich gedankt.

23 Ein im Freien liegender Stampflehmboden (Hofraum, Platz) kann zusätzlich siltig-organische Einschwemmungen sowie Frostspuren aufweisen (RENTZEL, in Vorb.: 5.1 Ein augusteischer Lehmboden), beides Merkmale für eine denudierte Oberfläche, die sich in Probe 92/34/3 nicht feststellen liessen.

24 Schicht 7 a weist eine Porosität von rund $25 \%$ auf.

25 Unter der Bezeichnung „Benutzungsschicht" verstehen wir ein während der Funktion der Baustruktur akkumuliertes Sedimentgemisch anthropogener Herkunft.

26 S. dazu auch Rentzel (in Vorb.), besonders Abb. 25.

${ }^{27}$ In einer an Probe 92/34/3 angrenzenden Ausgrabungsfläche wurde versuchsweise ein Feinabbau, bei dem alle Funde eingemessen wurden, durchgeführt. Dabei zeigte sich unter anderem, dass sich die Funde deutlich im Bereich von Schicht 6 konzentrieren. Freundliche Mitteilung von N. Spichtig.

28 Bestimmung: R. Macphail. Die menschlichen Koprolithen liegen als 0,1 bis $2 \mathrm{~mm}$ grosse Fragmente vor und können einen Anteil von bis $20 \%$ am Gesamtsediment erreichen, ein Anteil, der bei der Entstehung der Ablagerung sicher noch höher war, da Verwitterungsphänomene zur teilweisen Resorbierung der Koprolithen geführt haben. Zur Herkunft der menschlichen Fäkalien ist zu bemerken, dass diese nach oder während der Bildung der Planieschicht auf "natürliche" Weise ins Sediment gelangt sein dürften. Es ist aber auch denkbar, dass ein bereits koprolithenhaltiges Sediment ausplaniert wurde.

29 Unter dem Begriff "siltige Einschaltungen“ werden Gefügeveränderungen eines Sedimentes als Folge von Kompaktionen (z. B. Begehungen) verstanden.

30 Als typische mikromorphologische Anzeiger für backyard middens werden von MACPHAIL $(1994,24)$ folgende Komponenten erwähnt: menschliche Fäkalien, Hundekoprolithen, Knochen, Asche, organische Materialien, Phytolithen, Holzkohle, verbrannte Gramineen.

${ }^{31}$ Dass innerhalb dieser Planieschichten dennoch mit Begehungen zu rechnen ist, zeigt der Befund einer schlecht erhaltenen Feuerstelle, deren Oberkante sich nach Auskunft von N. Spichtig in eben dieser Planieschicht auf einer Höhe von ca. 254,67-254,72 m ü.M. befand, ohne dass jedoch ein sicheres Gehniveau fassbar gewesen wäre. Dies kann auf mögliche Abplanierungen hindeuten. S dazu auch Jud/SPICHTIG 1992, 28.

32 Z. B. Schicht 2 in Probe 92/34/3.

33 S. dazu auch D' Aujourd'Hul et al. 1976.

34 Neben Aufbringen von Bauschutt sind auch Abplanierungen, d.h. ein absichtlicher Abtrag von bereits ausplaniertem Material, denkbar. 


\section{Anhang}

\section{Abkürzungen}

AB Archäologische Bodenforschung

BaDpfl. Basler Denkmalpflege

BS Bodenscherbe

FK Fundkomplex

Fl. Fläche

$\mathrm{H} \quad$ Horizont

HGB Historisches Grundbuch

$\mathrm{HMB}$ Historisches Museum Basel

Inv.-Nr. Inventar-Nummer

$\mathrm{Jb} \quad$ Jahresbericht

KMBL Kantonsmuseum Basel-Land

Mk Münzkabinett (HMB)

MR Mauer

MVK Museum für Völkerkunde

NHM Naturhistorisches Museum

OF Oberfläche

OK Oberkante

P Profil

RMA Römermuseum Augst

RS Randscherbe

Sd Sonderdruck

SS Sondierschnitt

StAB(S) Staatsarchiv Basel-Stadt

UK Unterkante

WS Wandscherbe

Literatursigel (Zeitschriften, Reihen etc.)

ABS Archäologie in Basel. Materialhefte zur Archäologie in Basel

AS Archäologie der Schweiz

ASA Anzeiger für Schweizerische Altertumskunde

(B)Njbl. (Basler) Neujahrsblatt. Herausgegeben von der Gesellschaft zur Beförderung des Guten und Gemeinnützigen.

BUB Urkundenbuch der Stadt Basel, Bände 111. Herausgegeben von der Historischen und Antiquarischen Gesellschaft zu Basel, Basel.

BZ Basler Zeitschrift für Geschichte und Altertumskunde

JbAB Jahresbericht der Archäologischen Bodenforschung des Kantons Basel-Stadt

JbAK Jahresberichte aus Augst und Kaiseraugst

JbHMB Jahresbericht des Historischen Museums Basel-Stadt

JbSGUF Jahresbericht der Schweizerischen Gesellschaft für Ur- und Frühgeschichte

KDM BS Die Kunstdenkmäler des Kantons BaselStadt, Bände 1-5. Herausgegeben von der Gesellschaft für Schweizerische Kunstgeschichte, Basel.
NSBV Nachrichten des Schweizerischen Burgenvereins

SBKAM Schweizer Beiträge zur Kulturgeschichte und Archäologie des Mittelalters

ZAK Zeitschrift für Schweizerische Archäologie und Kunstgeschichte

ZAM Zeitschrift für Archäologie des Mittelalters

\section{Schriften der Archäologischen Bodenforschung}

Jahresberichte (JbAB)

Der Jahresbericht 1994 kann, solange vorrätig, zum Preis von Fr. 40.- bei der Archäologischen Bodenforschung bezogen werden. Die Jahresberichte 1988 bis 1993 sind zu Fr. 10.- noch erhältlich.

Materialhefte zur Archäologie in Basel (ABS)

Ergänzend zu den Jahresberichten wird in den Materialheften zur Archäologie in Basel eine repräsentative Auswahl von Basler Fund- und Dokumentationsmaterial vorgelegt. Mit der Schriftenreihe soll die abschliessende Berichterstattung über eine Grabung mit nachvollziehbarer Beweisführung und Auswertung des Fundmaterials ermöglicht werden.

Bisher erschienen und solange vorrätig noch erhältlich

Rudolf Moosbrugger-Leu, Die Chrischonakirche von Bettingen. Archäologische Untersuchungen und baugeschichtliche Auswertung. Mit einem Beitrag von Beatrice Schärli über die Münzfunde. Verlag Archäologische Bodenforschung Basel-Stadt, Basel 1985. Materialhefte zur Archäologie in Basel, Heft 1. 110 Textseiten, 78 Abbildungen, 6 Fototafeln und 3 Faltpläne. ISBN 3-905098-00-8. Fr. 15.-

Rudolf Moosbrugger-Leu, Peter Eggenberger, Werner Stöckli, Die Predigerkirche in Basel. Mit einem Beitrag von Beatrice Schärli über die Münzfunde. Verlag Archäologische Bodenforschung Basel-Stadt, Basel 1985. Materialhefte zur Archäologie in Basel, Heft 2. 133 Textseiten, 108 Abbildungen, 5 Faltpläne. ISBN 3-905098-01-6. Fr. 15.-

Peter Thommen, Die Kirchenburg von Riehen. Mit Beiträgen von Kurt Wechsler und Marcel Mundschin. Verlag Archäologische Bodenforschung Basel-Stadt, Basel 1993. Materialhefte zur Archäologie in Basel, Heft 5. 172 Textseiten, 135 Abbildungen, 15 Tafeln. ISBN 3905098-08-3. Fr. 40.-.

Thomas Maeglin, Spätkeltische Funde von der Augustinergasse in Basel. Mit einem osteologischen Beitrag von Jörg Schibler. Verlag Archäologische Bodenforschung Basel-Stadt, Basel 1986. Materialhefte zur Archäologie in Basel, Heft 6. 97 Textseiten, 33 Abbildungen, 14 Tafeln. ISBN 3-905098-02-4. Fr. 15.-

Dieter Holstein, Die bronzezeitlichen Funde aus dem Kanton BaselStadt. Verlag Archäologische Bodenforschung Basel-Stadt, Basel 1991. Materialhefte zur Archäologie in Basel, Heft 7. 95 Textseiten, 17 Abbildungen, 36 Tafeln, 1 Faltplan. ISBN 3-905098-09-1. Fr. 15.-.

Jacqueline Reich, Archäozoologische Auswertung des mittelalterlichen Tierknochenmaterials (10.-13. Jh.) von der Schneidergasse 8, 10 und 12 in Basel ( $\mathrm{CH}$ ). Mit einem Beitrag von Christoph Ph. Matt. 
Verlag Archäologische Bodenforschung des Kantons Basel-Stadt, Basel 1995. Materialhefte zur Archäologie in Basel, Heft 8. 84 Textseiten, 75 Abbildungen, 74 Tabellen. ISBN 3-905098-15-6. Fr. 45.-.

René Matteotti, Die Alte Landvogtei in Riehen. Ein archäologischer Beitrag zum Alltagsgerät derNeuzeit. Verlag Archäologische Bodenforschung des Kantons-Basel-Stadt, Basel 1994. Materialhefte zur Archäologie in Basel, Heft 9. 82 Textseiten, 56 Abbildungen, 33 Tafeln, 2 Farbtafeln. ISBN 3-905098-14-8. Fr. 40.-.

Pia Kamber, Die Latrinen auf dem Areal des Augustinerklosters, Basel-Augustinergasse 2, Grabung 1968. Mit einem Beitrag von F. Maurer zur Baugeschichte des Klosters. Weitere Beiträge von S. Jacomet (Archäobotanik), M. Joos (Sedimentologie), J. Schibler (Archäozoologie) und W.B. Stern (Archäometrie). Verlag Archäologische Bodenforschung des Kantons Basel-Stadt, Basel 1995. Materialhefte zur Archäologie in Basel, Heft 10. 153 Textseiten, 111 Abbildungen, 52 Tafeln, 5 Farbtafeln, 1 Falttafel. ISBN 3-905098-17-2. Fr. 45.-.

Marlu Kühn, Spätmittelalterliche Getreidefunde aus einer Brandschicht des Basler Rosshof-Areales (15. Jahrhundert AD). Verlag Archäologische Bodenforschung des Kantons Basel-Stadt, Basel 1996. Materialhefte zur Archäologie in Basel, Heft 11.78 Textseiten, 43 Abbildungen/ Diagramme, 87 Zeichnungen, 19 Tabellen. ISBN3-905098-19-9. Fr.45.-

Weitere Veröffentlichungen der Archäologischen Bodenforschung des Kantons Basel-Stadt

Rolf d'Aujourd'hui, Archäologie in Basel. Fundstellenregister und Literaturverzeichnis. Jubiläumsheft zum 25jährigen Bestehen der Archäologischen Bodenforschung Basel-Stadt. Herausgegeben von der Archäologischen Bodenforschung Basel-Stadt mit Unterstützung der Historischen und Antiquarischen Gesellschaft zu Basel. Verlag Archäologische Bodenforschung Basel-Stadt, Basel 1988. 179 Seiten, 5 Abbildungen. ISBN 3-905098-04-0. Fr. 10.-

Rolf d'Aujourd'hui, Die Entwicklung Basels vom keltischen Oppidum zur hochmittelalterlichen Stadt. Überblick Forschungsstand 1989. Zweite überarbeitete Auflage. Verlag Archäologische Bodenforschung Basel-Stadt, Basel 1990. 25 Textseiten, 35 Abbildungen. ISBN 3905098-05-9. Fr. 10.-. (Zur Zeit vergriffen, Neuauflage in Vorbereitung.)

Rolf d'Aujourd'hui, Basel Leonhardsgraben 47: Eine Informationsstelle über die mittelalterliche Stadtbefestigung im Teufelhof, Führer zur Ausstellung, Sd aus: Unsere Kunstdenkmäler 41, 1990.2, 169-180. Fr. 3.-
Rolf d'Aujourd'hui, Der Archäologische Park am Murus Gallicus, Führer durch die Ausstellung an der Rittergasse in Basel, Sd aus: Basler Stadtbuch 1993, 196-204. Fr. 3.-.

Ulrike Giesler-Müller, Das frühmittelalterliche Gräberfeld BaselKleinhüningen. Katalog und Tafeln. Basler Beiträge zur Ur- und Frühgeschichte, Bd. 11 B. Habegger Verlag, Derendingen-Solothurn 1992 221 Textseiten, 113 Tafeln, 1 Faltplan. ISBN3-85723-321-4. (Nur über Buchhandelerhältlich.)

Peter Jud (Hrsg.), Die spätkeltische Zeit am südlichen Oberrhein/Le Rhin supérieur à la fin de l'époque celtique, Kolloquium Basel, 17./18. Oktober 1991/Colloque de Bâle, 17/18 octobre 1991. Zweite, unveränderte Auflage. Verlag Archäologische Bodenforschung des Kantons Basel-Stadt, Basel 1995. 179 Seiten, zahlreiche Abbildungen. ISBN 3-905098-13-X. Fr. 40.-.

\section{Bestellmöglichkeiten}

Die Hefte werden von der Archäologischen Bodenforschung und vom Seminar für Ur- und Frühgeschichte der Universität Basel im Selbstverlag herausgegeben und sind über den Buchhandel oder beim Verlag direkt erhältlich. Bestellungen sind zu richten an: Archäologische Bodenforschung Basel-Stadt, Petersgraben 11, 4051 Basel.

Einzelbestellung. Es gelten die oben erwähnten Preise zuzüglich Versandkosten.

Abonnement Materialhefte. Der Preis je Heft beträgt Fr. 35.- zuzüglich Versandkosten. Die Auslieferung erfolgt jeweils nach Erscheinen eines Heftes.

Abonnement Jahresbericht. Der Preis je Jahrgang beträgt Fr. 30.- zuzüglich Versandkosten.

Wenn Sie Jahresbericht und Materialheft abonniert haben, gewähren wir Ihnen einen Rabatt von Fr. 10.auf den Abonnements-Preis des Jahresberichtes. 